\title{
Nuevo sistema de transporte público en el Área Metropolitana de Mendoza, Argentina. Algunas reflexiones sobre movilidad
}

(4) Julieta Dalla Torre

Instituto Multidisciplinario de Estudios Sociales Contemporáneos, Consejo Nacional de Investigaciones Científicas y Técnicas / Universidad Nacional de Cuyo, Argentina.

Recibido: 25 de abril de 2019. Aceptado: 2 de diciembre de 2019.

\begin{abstract}
Resumen
Actualmente la movilidad cotidiana tiene lugar en contextos cada vez más complejos propios de las ciudades neoliberales. De ahí la relevancia de los sistemas de transporte urbano que aseguren este derecho humano asociado con la satisfacción de las necesidades básicas de la población. El artículo indaga el nuevo sistema de transporte público de pasajeros del Área Metropolitana de Mendoza (AMM), ciudad intermedia del centro-oeste argentino, inaugurado el pasado mes de enero. Algunas de las preguntas a responder son: qué características presenta este nuevo sistema de transporte y cuál es el acceso a la movilidad que supone entre residentes de barrios periféricos del AMM y, entonces, a la apropiación, producción y reproducción diaria de la ciudad. Se parte del supuesto de que el sistema de transporte público contribuye a formas desiguales de movilidad al interior de las ciudades. La indagación utiliza herramientas metodológicas cualitativas como análisis documental, observación en campo y entrevistas individuales.
\end{abstract}

Palabras clave: Transporte colectivo. Movilidad cotidiana. Periferia urbana. Políticas públicas.

New public transport system in the Metropolitan area of Mendoza, Argentina. Some reflections on mobility

\begin{abstract}
Nowadays, daily mobility takes place in increasingly complex contexts typical of neoliberal cities. Hence the relevance of urban transport systems that ensure this human right associated with meeting the basic needs of the population. The article analyses the new public passenger transport system in the Metropolitan Area of Mendoza (AMM), an intermediate city in the center-west of Argentina, inaugurated last January. Some of the questions to be answered are: what are the characteristics of this new transport system and what is the access to mobility between residents of peripheral neighborhoods of the AMM and, therefore, to the appropriation, production and daily reproduction of the city. It is assumed that the public transport system
\end{abstract}


contributes to unequal forms of mobility within cities. The inquiry uses qualitative methodological tools such as documentary analysis, field observation and individual interviews.

Keywords: Collective transport. Daily mobility. Urban periphery. Public politics.

Palavras-chave: Transporte coletivo. Mobilidade cotidiana. Periferia urbana. Políticas públicas.

\section{Introducción}

El presente artículo centra su análisis en el sistema de transporte del Área Metropolitana de Mendoza (AMM), cuarta aglomeración de la República Argentina, ciudad intermedia ubicada al centro-oeste del país. Actualmente, esta ciudad se encuentra transitando un proceso de transformación de su sistema de transporte de pasajeros a partir de la implementación del llamado Mendotran desde enero de 2019.

Se entiende que la movilidad cotidiana es fundamental para garantizar el derecho a la ciudad en las metrópolis contemporáneas, las cuales son escenarios sociales cada vez más desiguales. El transporte público constituye un servicio central para asegurar la posibilidad de movilidad de las poblaciones y su posible participación en la construcción urbana. Así, el Estado a partir de la implementación de un sistema de transporte público condiciona su movilidad y esto a su vez reconfigura las ciudades y sus posibilidades de participar de su construcción cotidiana. De ahí la relevancia de indagarlo y compararlo con el sistema de transporte anterior, vigente en el AMM durante las tres últimas décadas.

Surgen algunas preguntas a responder como: ¿cómo es el sistema de transporte en otras ciudades de América del Sur?, ¿cuáles son las características que presenta el nuevo sistema de transporte público del AMM?, ¿qué similitudes y diferencias presenta con el sistema anterior?, ¿cuál es el rol de estas políticas de transporte en las posibilidades de movilidad urbana al interior del AMM y particularmente entre residentes de áreas periféricas de esta Ciudad? En síntesis, ¿¿cuáles son las oportunidades que el Estado les brinda mediante el sistema de transporte y en qué medida contribuye a asegurar su derecho a la ciudad?

Se parte del supuesto inicial de considerar que el nuevo sistema de transporte público colectivo implementado en el AMM sostiene formas desiguales de movilidad que no contribuye a habilitar prácticas más colectivas de construcción cotidiana de la ciudad.

Para analizar la vinculación transporte-movilidad, se toma la última intervención estatal en materia de transporte realizada en el AMM, el Mendotran. La estrategia metodológica diseñada supuso la combinación de la consulta de datos secundarios relevados con instrumentos de medición aplicados con anterioridad en el área de estudio (Encuestas de Origen-Destino 1998, 2005, 2010), la revisión y análisis de documentos oficiales (Plan Integral de Movilidad Sustentable Área Metropolitana del Gran Mendoza, 2030; Ley Provincial de Movilidad de Mendoza 9.086 del año 2018; Decreto 1.512 de septiembre de 2018; Ley de Tránsito 6.082 de 1993), y el relevamiento en campo.

Dicho trabajo en terreno ha requerido de la técnica de la entrevista individual. Ésta ha sido aplicada a usuarios y usuarias del nuevo sistema de transporte, entre febrero y marzo de 2019, luego de la implementación del nuevo sistema público de transporte colectivo. Se han explorado algunas categorías de análisis construidas para indagar la relación entre transporte y movilidad cotidiana de la población de las áreas periféricas de la urbe mendocina, fundamentalmente vinculadas al nuevo sistema de trasporte, su uso y las similitudes y diferencias respecto del sistema anterior: tipo de medio de 
movilidad colectivo utilizado para trasladarse en la ciudad, tiempo estimado de duración del viaje, distancia recorrida, motivo del viaje, opinión respecto del nuevo sistema de transporte, comparación con el sistema anterior, calidad del servicio (coches, vías de movilidad, sistema de pago, disponibilidad del servicio), precio del boleto.

El trabajo en terreno también implicó la técnica de la observación directa, fundamentalmente de la infraestructura disponible: paradas de colectivos, señalética, calles y demás vías de acceso, dársenas para recorridos troncales, puntos de recarga de tarjetas Red Bus, puestos de información disponibles. Por otro lado, el uso de la cartografía y de los Sistemas de Información Geográfica (SIG), permitieron analizar los recorridos disponibles, la distribución espacial de los mismos, las diferencias al interior del AMM, y puntualmente identificar el área de la indagación realizada en campo. Se determinó así una zona en el noreste del departamento de Las Heras, ubicada al noreste del AMM, en el denominado Barrio Tamarindos. El mismo se encuentra en una de las áreas más pobres de la aglomeración, con acceso a una vía troncal de transporte hacia la Capital, pero con una menor conectividad intradepartamental.

El presente artículo ha sido organizado en cinco apartados; el mismo comienza con un recorrido teórico por los conceptos que lo cruzan. A continuación, se reconstruyen los principales antecedentes de estudios referidos a movilidad y transporte en América del Sur. En tercer lugar, se caracterizan y comparan algunos sistemas de transporte de ciudades sudamericanas. Luego se caracteriza al AMM y se analiza su sistema de transporte a lo largo de las últimas tres décadas. En quinto lugar, la indagación se focaliza en el Mendotran, se identifican continuidades y diferencias entre el nuevo sistema y el anterior, y se analiza el acceso a la movilidad cotidiana que supone entre residentes de la periferia. En sexto lugar, se desarrollan algunas consideraciones finales vinculadas a las políticas de transporte urbano, a la movilidad cotidiana con énfasis en las áreas periféricas del AMM y al derecho a la ciudad. Por último, se incluyen las referencias bibliográficas y demás fuentes consultadas.

\section{La movilidad y otras categorías centrales}

La movilidad es "una práctica social de desplazamiento en el territorio" (Gutiérrez, 2012:65). También, puede ser entendida como capital potencial y como práctica de acceso (Vecchio, 2019). Como capital se la entiende como la capacidad de acceso que brinda a los agentes sociales la posibilidad de desarrollar actividades en determinados lugares; distintas formas de accesibilidad. Es una especie de capital específico que da cuenta de los recursos potenciales y actuales que permite movilizarse en el espacio urbano. Sin embargo, como todo capital, también la movilidad está disponible de manera diversa, en el sentido de que no todos los agentes sociales tendrán iguales posibilidades de acceso a la movilidad, con lo cual se generarán desigualdades y formas de exclusión. De hecho, existen cuestiones individuales, sociales y espaciales que condicionan las posibilidades de moverse espacialmente por parte de un agente, involucrando también distintas escalas espaciales.

Como práctica de acceso, la movilidad es aquella forma en que cada agente social la utiliza para acceder a determinado lugar y/o actividad. Avellaneda y Lazo (2011) y Landon (2013), al igual que Gutiérrez (2012), la definen como una acción social de desplazamiento en un determinado territorio y tiempo que permite el acceso a la ciudad, a sus territorios, a actividades, a las oportunidades que la urbe brinda y a relacionarse socialmente con los otros. Asimismo, manifiestan que en ésta se conjugan deseos o expectativas, necesidades y capacidades o recursos objetivos y subjetivos de cada uno de los agentes sociales. 
Tal como afirma Gutiérrez y Rearte (2007) debe concebirse a la movilidad en estrecha relación con el territorio, cualquiera sea la escala de análisis. Es decir, que los procesos de movilidad urbana se encuentran condicionados y a la vez condicionan las características que presentan los territorios en un determinado momento histórico. Se da entre ellos una relación dialéctica. Por ello, nunca se les puede considerar de manera aislada: "Las prácticas sociales de desplazamiento expresan el uso del territorio" dice Gutiérrez (2012:67). A su vez, remiten a procesos materiales y subjetivos; es decir, a desplazamientos reales, pensados y posibles.

La movilidad es determinante del desarrollo de las dinámicas de la ciudad, lo que "la convierte en un dispositivo importante de promoción de la inclusión social para los grupos más pobres, en la medida que les permite el acceso a las oportunidades y a los servicios que ofrece la ciudad generando así una mayor integración" (Avellaneda y Lazo, 2011:48). En consecuencia, la inclusión social se vincula estrechamente con las posibilidades de movilidad de las personas, las cuales están condicionadas por la situación social.

Es importante realizar una distinción entre el concepto de movilidad urbana que "remite a todas las movilidades de diferente escala espacial y temporal realizadas en el ámbito de un sistema urbano" (Gutiérrez, 2012:62) y el de movilidad cotidiana, entendida como "la migración pendular entre el hogar y el trabajo u otras actividades" (Gutiérrez, 2012:62). En el marco de la movilidad cotidiana los agentes sociales hacen uso de los servicios de transporte disponible en las ciudades. El transporte es el medio utilizado para realizar el desplazamiento en el territorio cuando ocurre la movilidad (Gutiérrez, 2012).

El término servicio público de transporte puede definirse como aquella prestación por parte del Estado o por un tercero por este contratado bajo el Derecho público, con el objetivo de satisfacer necesidades de la población vinculadas con el traslado de personas o bienes. En las ciudades pueden existir diversos medios de transporte para desplazarse de lugar en lugar; no obstante, no todos los agentes sociales tienen iguales posibilidades de acceso, ni pueden en consecuencia hacer un mismo uso.

Asimismo, el sistema de transporte está fuertemente vinculado con la posibilidad de acceso a la ciudad y a sus oportunidades. De este modo, ayuda a diferenciar y segmentar social y territorialmente las ciudades entre el centro y las periferias y en sus interiores. Según Cebollada y Avellaneda (2008) existen tres variables fundamentales que condicionan el uso de los medios de transporte por parte de una población y su desplazamiento y que hacen a su eficiencia: la cobertura territorial del sistema de transporte, lo que significa que permita a la población el acceso a lugares donde desee trasladarse; el horario de funcionamiento que presente una extensión tal que permita acceder durante todo el día, y el costo de su uso, es decir, que sea accesible viajar.

Es bien sabido que las clases más vulnerables deben destinar gran parte de sus ingresos y tiempo en el desplazamiento en las ciudades, aun cuando se movilizan poco en comparación a otras clases sociales (Moreno Luna, 2016). El tiempo de desplazamiento es un indicador usado para dar cuenta del grado de segregación al que pueden ser obligados determinados grupos sociales. En este sentido, se entiende el transporte colectivo como una herramienta importante para combatir la pobreza urbana y de promoción de la inclusión social (Moreno Luna y Rubiano Brínez, 2014).

En consecuencia, dependerá del diseño, planificación y posterior aplicación que se haga del sistema de trasporte público urbano en un determinado territorio, que ayude a la reducción de la desigualdad en el acceso a las oportunidades urbanas o al derecho a la ciudad y así a la igualdad en la movilidad o, por el contrario, que aumente, profundice 
y así perpetúe la segregación. Esta es entendida como aquella situación que implica un proceso de diferenciación social; una disposición espacial desigual de grupos sociales que homogeiniza en su interior y diferencia respecto de los otros (Rodríguez Vignoli, 2001; Vidal-Koppmann, 2007; Moreno Luna y Rubiano Bríñez, 2014); la organización del espacio en zonas de fuerte homogeneidad social interna y de fuerte disparidad social entre ellas (Castells, 2014). "Este proceso de diferenciación puede asociarse con una diferenciación de la movilidad según las condiciones socioeconómicas y locacionales del barrio de residencia (central, periférica, intersticial)" (Moreno Luna, 2016:58-59).

Los territorios son construcciones sociales y, por tanto, históricas (Benedetti, 2011), componentes fundamentales de los procesos de movilidad urbana. Se entiende con Raffestin (1993) que los territorios son una construcción social a partir del espacio geográfico, a partir de una acción de apropiación material o simbólica del espacio por parte de un actor. En este sentido, cuando un actor se apropia de un espacio en forma concreta o abstracta se dice que lo territorializa (Dalla Torre y Ghilardi, 2018).

De acuerdo, a la definición que hace el Plan Provincial de Ordenamiento Territorial de Mendoza, los territorios urbanos son aquellas áreas que se definen como las zonas de mayor densidad poblacional (+30hab./ha. de la provincia), en las cuales los usos del suelo característicos son residenciales, de esparcimiento, comerciales y de servicios (Secretaría de Ambiente y Ordenamiento Territorial, 2017). Los territorios urbanos centrales son fundamentalmente aquellos contenidos en la Capital de Mendoza y más precisamente en el conocido "Centro" de esta ciudad Capital, área de mayor actividad de la urbe. Por su parte, los territorios periféricos son aquellos que se ubican en las consideradas áreas marginales de la ciudad, en nuestro caso, las áreas del AMM más alejadas de la Capital. Hablar de estos territorios periféricos es importante en el marco de este estudio sobre transporte y movilidad porque como dice Soldano (2013:84) "Si bien las periferias son tan antiguas como las ciudades, sostengo que el hecho de habitarlas, en el presente, está moldeando formas subjetivas y de ciudadanía (...) de nuevo tipo”.

Justamente la presente investigación busca analizar el nuevo sistema de transporte urbano del AMM con el objetivo de vincularlo con el acceso a la movilidad cotidiana, fundamentalmente en los barrios periféricos de esta Ciudad.

\section{Estudios sobre sistemas de transporte en América del Sur}

Las transformaciones en las ciudades en Sudamérica, particularmente desde el último cuarto del siglo XX, se han dado en general sin previsión ni planificación y han producido transformaciones importantes en los hábitats urbanos. Se han conformado así lugares periféricos respecto de los centros sin la infraestructura necesaria para el desarrollo cotidiano de la vida. Ésta ha dejado de desarrollarse en espacios próximos al hogar para pasar a desplegarse de manera dispersa a lo largo de una extensa trama urbana. Los servicios han perdido expansión y cobertura tanto social como territorial (Gutiérrez, 2010), dejando parte de la población afuera. Comienza así a darse una separación y posteriormente un extrañamiento entre las partes. Se dice entonces, que las ciudades se van dividiendo en diversos fragmentos o islas, transformándose en lo que Janoschka (2006) denomina "ciudad de islas". Las ciudades se expanden y aumentan las desigualdades en su interior:

(...) se presenta una periurbanización lejana y dispersa al mismo tiempo que (...) urbanizaciones densas y continuas, pero no "industrializables", sea por situaciones de inseguridad (inaccesibilidad física) o marginalidad (inaccesibilidad económica). (...) La ciudad territorialmente expandida, como una región urbanizada con límites 
difusos e internamente discontinua, es un patrón extendido por todo el mundo, y también compartido por las grandes ciudades latinoamericanas (Gutiérrez, 2005).

Los procesos de expansión espacial en las ciudades arriba explicitados pueden evidenciarse en su expansión y en los espacios ocupados por las distintas clases sociales. En términos generales, una gran proporción de las clases medias y altas se han ubicado en las afueras de las aglomeraciones, en desarrollos inmobiliarios de gestión privada, los denominados barrios cerrados. Por su parte, las clases populares o de menores ingresos se han ido localizando (mayormente de forma compulsiva e involuntaria, obligadas por la necesidad) por fuera de las áreas centrales de las ciudades, en los territorios urbanos periféricos, con ausencia o limitación de servicios básicos, entre éstos, el sistema público de transporte.

Paralelamente, se han desarrollado políticas en materia de transporte urbano que han promocionado fuertemente la movilidad individual en la figura del automóvil y han liberalizado y privatizado el transporte colectivo, fortaleciendo la gestión privada del mismo, lo que ha significado el abandono de la gestión pública y de los subsidios. Las clases de menores recursos que no poseen automóvil quedan atadas al sistema de transporte colectivo para asegurar su movilidad, de ahí su importancia y la necesidad de que este sistema les contribuya en su acceso a la ciudad.

Surgen entonces las siguientes preguntas: cómo articular los fragmentos que hoy caracterizan a las ciudades sudamericanas y cómo asegurar que sus habitantes puedan movilizarse y con ello participar en su construcción colectiva. Dado que se considera que la movilidad cotidiana y los sistemas de transporte son una respuesta central a dicho interrogante, se reconstruyeron antecedentes de investigaciones centradas en el análisis de la movilidad y el transporte en distintas ciudades.

Lizárraga Mollinedo (2006) hace una indagación general de la movilidad urbana sostenible en las grandes ciudades actuales del mundo. También, Sheller y Urry (2006) desarrollan un nuevo paradigma de la movilidad dadas las diversas formas existentes y la transformación que éstas están suponiendo en el espacio y la sociedad. Por su parte, Vecchio (2018) en su tesis doctoral se centra en el impacto que la movilidad diaria urbana puede tener sobre las oportunidades disponibles de cada persona. Otro trabajo de este autor (Vecchio, 2019) discute los conceptos teóricos dominantes del paradigma de movilidad del Norte desde las ciudades periféricas del Sur y los enriquece desde esta perspectiva de las movilidades que, en general, no es considerada en los estudios; para ello trabaja sobre relatos de movilidades cotidianas en dos barrios periféricos de la Ciudad de Bogotá.

En Colombia, hay un importante desarrollo de investigaciones referidas a la movilidad urbana de la población. Se puede citar a Moreno Luna y a Rubiano Brínez, cuyos trabajos están dedicados a movilidad y exclusión social en el municipio de Soacha, Bogotá. En Moreno Luna (2016), se analiza en qué medida los procesos de metropolización generan segregación socioespacial. En Moreno Luna y Rubiano Bríñez (2014) se observan los niveles de segregación que presentan residentes de un macroproyecto de vivienda denominado Ciudad Verde, ubicado en Soacha, periferia del sur de Bogotá, debido fundamentalmente a los problemas de movilidad cotidiana a los que se encuentran sometidos diariamente.

El estudio de Avellaneda y Lazo (2011:48) refiere a un análisis comparativo de la movilidad cotidiana en áreas periféricas de las ciudades de Lima, Perú, y Santiago, Chile. Observan el vínculo entre el alcance al sistema de transporte público y las situaciones de pobreza y exclusión; sostienen que "los medios de transporte dejan de ser meros instrumentos para desplazarse para adquirir una función social más allá del propio desplazamiento". En la Ciudad de Lima el sistema de transporte ha sido tradicionalmente 
desregulado y, buena parte del mismo, informal, fundamentalmente aquel de las áreas periféricas de la ciudad. Actualmente, cuenta con un sistema de carácter troncal similar al de otras ciudades sudamericanas como Bogotá, Curitiba y Santiago.

En Chile, Roa et al. (2013) indagan la relación entre exclusión social y sistema de transporte para identificar los patrones espaciales de movilidad de la ciudad intermedia de Los Ángeles en la región del Bío Bío; se basan en datos de la Encuesta de Origen-Destino 2004. Por su parte, Jouffe y Lazo (2010) hacen un estudio de las prácticas cotidianas de movilidad de pobladores pobres en áreas periurbanas de la ciudad de Santiago. Es muy interesante el análisis político que hacen de dichas prácticas y rescatan por su intermedio las relaciones de poder que existen entre los agentes sociales usuarios de los sistemas de transporte público disponibles y estos dispositivos de movilidad, que son entendidos desde una perspectiva foucaultiana como dispositivos de control de la población urbana.

En Argentina, Gutiérrez (2005) analiza el sistema de transporte mercantil de pasajeros urbanos en América Latina haciendo foco en la Ciudad Autónoma de Buenos Aires (CABA) y su cruce con los nuevos requerimientos de movilidad que plantean las ciudades actuales; destaca la importancia del transporte para la inclusión social. Gutiérrez y Rearte (2007) trabajan los procesos de segregación y los servicios de transporte y los vinculan con las políticas urbanísticas de la CABA en dos casos de reocupación urbanística con condiciones socioeconómicas y de infraestructura muy distintas. Ortiz y Spirtu (2012) analizan la inclusión de un corredor de colectivos en carriles exclusivos a lo largo de la Avenida 9 de Julio; el trabajo muestra los intereses políticos que el gobierno de la Ciudad privilegió por sobre los sociales.

Además, Segura (2012) estudia la vinculación clase social-espacio urbano desde un trabajo etnográfico sobre el área periférica de la Ciudad de La Plata, provincia de Buenos Aires. Se detiene en una crítica de la noción de segregación residencial socio-económica para pensar la desigualdad en las ciudades latinoamericanas y enfatiza que además de las residencias urbanas, se deben analizar los desplazamientos e interacciones sociales de los ciudadanos de la periferia. Segura (2013) compara dos espacios segregados socioespacialmente de la Ciudad de La Plata, para comprender los modos de simbolizar y habitar el espacio urbano. Por su parte, Soldano (2013) aborda la cuestión social urbana y la desigualdad centrada en la relegación social y urbana y la movilidad cotidiana. La autora considera que el Estado y las políticas públicas tienen un rol clave en la reproducción de los intercambios desiguales y el confinamiento material y simbólico de los conjuntos sociales que habitan las periferias urbanas. Toma como caso de estudio la periferia noroeste de la Región Metropolitana, una zona del partido de José Clemente Paz, e indaga el ex tren San Martín que presta un servicio diferenciado para cartoneros.

Asimismo, trabajos como los de Rey y Parras (2012) estudian la movilidad cotidiana urbana en la ciudad de Resistencia, provincia de Chaco, a partir de la combinación de metodologías cuantitativas y cualitativas y proponen herramientas muy interesantes para su estudio. Por su parte, Devito, García y Martínez (2016) analizan el concepto de movilidad urbana sostenible y su aplicabilidad en el AMM, área de estudio de la presente investigación. García Schilardi (2014) indaga el transporte público del AMM con datos de la Encuesta de Origen y Destino 2010 aplicada en la provincia y lo vincula con los procesos de inclusión social urbanos.

\section{Similitudes en los sistemas de transporte urbano sudamericanos}

Las políticas de transporte público colectivo urbano de las últimas dos décadas en gran parte de los países de América del Sur presentan marcadas similitudes: la Red 
Integrada de Transporte (RIT) en Curitiba, Brasil; el TransMilenio en Bogotá, Colombia; el TransSantiago, en Santiago, Chile; el Metrobus en Buenos Aires y el Mendontran, en Mendoza, ambos en Argentina. En general, todas éstas involucran sistemas de buses rápidos y tronco alimentados (en inglés Bus Rapid Transit - BRT) y expresan entre sus objetivos mejorar la integración de las poblaciones, fundamentalmente los grupos más pobres que viven en las periferias urbanas.

La Ciudad de Curitiba -capital del Estado de Paraná, ubicado al sur de Brasil- fue la primera en desarrollar una política municipal de movilidad entendida como una Red Integrada de Transporte hacia el año 1968 cuando se aprobó el Plan General de Curitiba, el cual cubre la Ciudad de Curitiba y otros municipios que conforman la Región Metropolitana de Curitiba. La RIT fue concebida con el objetivo de disminuir la presencia de automóviles en el anillo central de la aglomeración aumentando el uso del transporte público de autobuses frente al aumento sostenido de la población. El Plan involucra no sólo la reforma de la red vial sino también el uso del suelo urbano. Así, el mismo contempla un gran número de espacios verdes, calles peatonales y el uso de la bicicleta a través de carriles exclusivos (RES, 2011). Este sistema que permite el transporte del alrededor del $85 \%$ de la población de Curitiba ha sido el modelo del BRT de otras ciudades de Brasil, así como del TransMilenio de Bogotá, el Transantiago de Santiago, el Metropolitano de Lima, Perú, el Metrobús de la Ciudad de México, la Orange Line de Los Ángeles, entre otras (Marre, Barbosa, Martínez, 2015:92).

El sistema de transporte de Bogotá, Colombia, fue transformado hacia el año 2000 y se inauguró el TransMilenio, como sistema de buses rápidos o BRT. El proyecto no sólo buscaba mejorar el transporte de la ciudad sino también la inclusión social; este debería ser un lugar de encuentro entre todos los ciudadanos; asimismo, intentaba "ofrecer un servicio de transporte público más confiable para el centro y las periferias, sirviendo a grupos sociales diferentes, requiriendo inversiones más bajas que las de un sistema de metro" (Vecchio, 2019:190).

Posteriormente, hacia el año 2007, en la Ciudad de Santiago de Chile se implementó un nuevo sistema de transporte colectivo denominado Transantiago. Si bien el mismo está concesionado en agentes privados, pertenece al Estado, lo que significó en su momento un cambio importante respecto del sistema de transporte privado anterior impuesto en los años setenta por la dictadura militar. Este sistema de transporte reemplazó al de microbuses amarillos, las llamadas "micros amarillas". Al respecto, Lazo (2008:2) afirma: "A partir de los años setenta las micros fueron apropiándose del espacio de la capital y dominando el paisaje santiaguino. (...) un sistema de micros caótico, sin ley ni orden, que funcionaba al día y según la lógica del libre mercado". Además, este sistema privilegiaba el uso del automóvil individual, fundamentalmente entre las clases medias $\mathrm{y}$ altas.

El Transantiago lo conforman tres medios de transporte que constituyen la Red Metropolitana de Movilidad de la Ciudad de Santiago: los buses, el Metro Santiago y el MetroTren Nos. Se divide en líneas troncales que se trazan por el exterior de las zonas residenciales de la urbe y líneas alimentadoras de buses que conectan los barrios con las primeras. El mismo ha significado grandes cambios en la configuración de la red de buses, en la transformación completa de estos, la unificación tarifaria a partir de una tarjeta de pago única, la construcción de infraestructura como carriles de circulación, paradas, estaciones y cambios en el sistema de gestión. "Transantiago no sólo fue presentado como la solución frente a los problemas de los microbuses sino que también era uno de los medios para convertir a Santiago en una ciudad de clase mundial, moderna y competitiva a nivel internacional" (Jouffe y Lazo, 2010:31). Actualmente, existen problemas en la cobertura horaria y espacial y también con el elevado precio del boleto. Asimismo, grandes zonas suburbanas han 
quedado desconectadas del centro de la Ciudad de Santiago, con las consecuencias sociales que ello significa en términos de movilidad de la población y de su segregación material y simbólica.

El sistema de transporte de la Ciudad Autónoma de Buenos Aires se encuentra organizado en el marco del denominado Metrobus, que combina colectivos articulados y tradicionales con carriles exclusivos. Este sistema alcanza los $62,5 \mathrm{~km}$ de extensión y cuenta con centros de trasbordo cuyo fin es promover la intermodalidad y facilitar las combinaciones de colectivos, trenes, subtes y bicicletas rentadas, además de disponer de espacios de espera más confortables y seguros. El Metrobus busca disminuir los tiempos de viaje y brindar previsibilidad, comodidad, seguridad y mejorar la calidad ambiental según se afirma, así como promover un cambio de uso que reemplace el auto particular como transporte individual por el transporte público colectivo. Asimismo, se dice que la Red de Metrobus CABA genera una revitalización de los barrios de la Ciudad al transformar el espacio público. La participación comunitaria también es rescatada y resaltada como un valor importante: "vecinos y comerciantes de cada barrio participan en la toma de decisiones que permiten mejorar la convivencia y cuidar los espacios compartidos todos los días" (Desarrollo Urbano y Transporte, s/f b).

Actualmente el Área de Desarrollo Urbano y Transporte del gobierno de la CABA diseña, según manifiesta, políticas e instrumenta los programas y proyectos destinados al planeamiento urbano y a la ejecución y fiscalización de obras públicas de la Ciudad: "Trabajamos por un transporte público sustentable y de calidad, para que el vecino cada día viaje de forma más rápida, cómoda y segura" (Desarrollo Urbano y Transporte, s/f a). Ortiz y Spirtu (2012:201-202), quienes trabajan sobre el Metrobus, sostienen que hoy las políticas buscan la integración de los medios de trasporte para lograr que se "adopten patrones de desplazamientos racionales y (...) minimicen los costos sociales que estos desplazamientos imponen (...) (en tiempo, ocupación de espacio, costo, contaminación)". No obstante, se coincide con Jouffe y Lazo (2010:37) cuando afirman que:

(...) se trata de la puesta en práctica de políticas modernizadoras vía el sueño del autofinanciamiento del transporte público por medio de los propios usuarios, de la baja inversión del Estado y del mejoramiento de la calidad de vida de los ciudadanos por la eficiencia del sistema. El usuario es reducido a una fuente de ingreso (...), que no se beneficiaba de la ayuda estatal pero sí de su propia participación para la eficiencia del sistema. Este "usuario abstracto" (...) aceptará los múltiples inconvenientes concretos de la reforma contra una ganancia en el tiempo de desplazamiento.

\section{El área metropolitana de Mendoza, Argentina}

El Área Metropolitana de Mendoza (Figura 1), contexto de estudio del presente artículo, constituye la cuarta ciudad argentina en número de habitantes después de Buenos Aires, Córdoba y Rosario. Es considerada la mayor área urbana de la provincia, cuenta con un total de 872.311 habitantes -según el último Censo Nacional de Población, Hogares y Viviendas (INDEC, 2010)- y representa el 50\% aproximadamente de la población total de la provincia de Mendoza, que hacia el 2010 alcanzaba a 1.738.929 habitantes. 


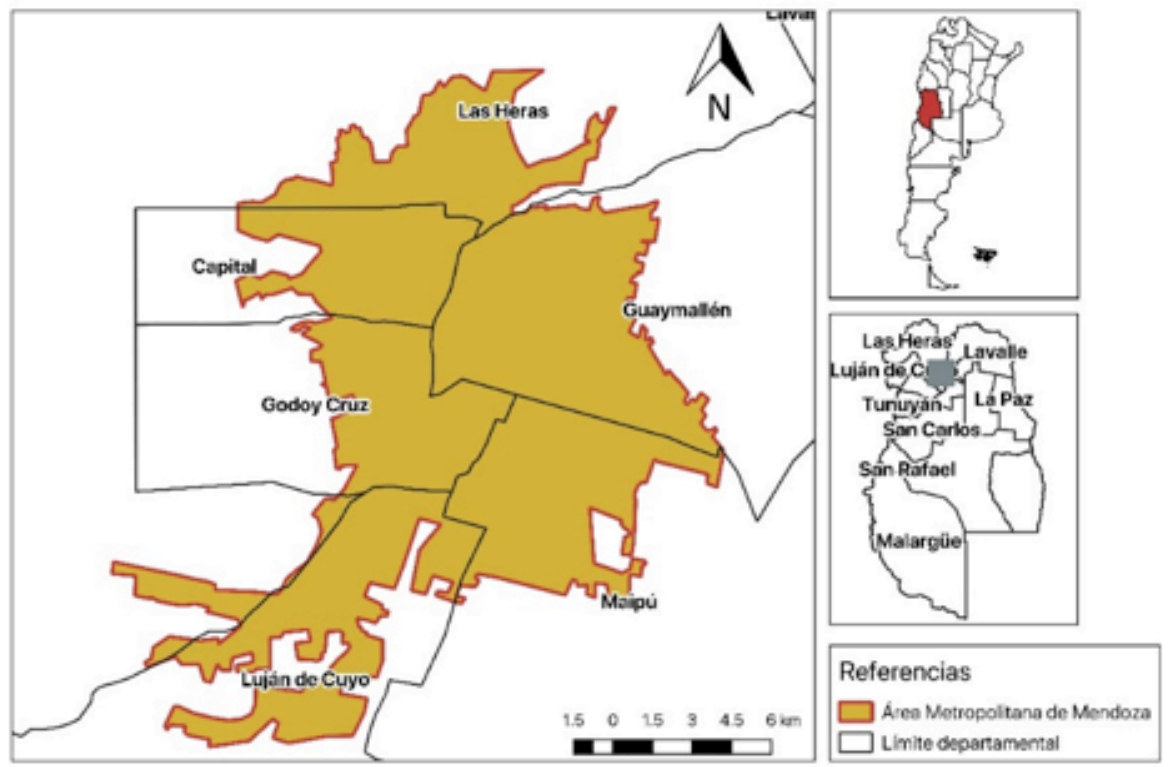

Figura 1. Área Metropolitana de Mendoza, Argentina. Fuente: elaboración propia, con la colaboración de Matías Ghilardi.

El núcleo del AMM se organiza alrededor de la Ciudad de Mendoza o departamento Capital, el cual se fue extendiendo fundamentalmente en las últimas dos décadas hacia las localidades vecinas de Luján de Cuyo, Maipú, Guaymallén, Las Heras y Godoy Cruz. Estas seis localidades conforman los seis departamentos (forma de organización administrativa de la provincia) del AMM. En el departamento Capital se encuentra el centro o microcentro que presenta gran parte de las actividades provinciales comerciales, bancarias, administrativas, así como el Centro Cívico que alberga al poder judicial provincial, a la sede de los tribunales federales radicados en Mendoza, a la Casa de Gobierno (Sede del Poder Ejecutivo Provincial), al Edificio de la Agencia de Administración Tributaria de Mendoza y a la Municipalidad de la Ciudad de Mendoza.

El AMM muestra una expansión explosiva en el periodo 2000-2010, durante el cual se dispara la competencia por el uso del suelo. Actualmente, esta mancha conocida como Gran Mendoza se encuentra en constante expansión fundamentalmente hacia el oeste -la denominada zona del piedemonte- y hacia el sur, invadiendo áreas anteriormente ocupadas con viñas y olivos para usos agrícolas; se ocupan así áreas intersticiales o de interfase entre los espacios urbanos consolidados y los rurales.

Existen normativas que buscan regular el uso y apropiación de los espacios urbanos, tanto a nivel provincial como de los municipios que integran el AMM. Ejemplos de éstas son la Ley de Ordenamiento Territorial de Mendoza (8.051) sancionada en el año 2009 y el Plan Provincial de Ordenamiento Territorial que en 2017 fue promulgado Ley (8.999), constituyéndose en la primera herramienta operativa del ordenamiento territorial (OT) que busca "el desarrollo sustentable del territorio" (Secretaría de Ambiente y Ordenamiento Territorial, 2017:11). Más allá de la existencia de estas importantes herramientas regulatorias, se distingue una fuerte desarticulación y falta de coordinación intra-AMM y puntualmente entre los municipios que la integran, lo cual favorece las excepciones arriba explicitadas y, por lo tanto, el avance del mercado en la apropiación de los espacios. A su vez, las normativas vigentes suelen ser ignoradas por vías de excepción, a partir de las cuales se permite la urbanización de áreas inhibidas para su edificación. 
El desarrollo espontáneo y desordenado del AMM se replicó en el sistema vial. Barbosa, Marre y Martínez (2016:8) afirman: "Esta falta de ordenamiento perjudicó la fluidez del tránsito, no previó la superposición de recorridos en forma concéntrica, generó un desequilibrio con una sobreoferta en el centro y una deficiente oferta en otros sectores de la ciudad, y no permitió lograr una correcta conectividad y cobertura". Si bien, se encuentran intentos de articulación de su sistema de transporte entre los distintos niveles gubernamentales, aún no se logra "una regulación armónica y coherente entre los distintos instrumentos normativos" (Barbosa, Marre y Martínez, 2016:13). En consecuencia, existe una superposición de instrumentos vigentes de distintas oficinas y niveles gubernamentales, también contradicciones entre estos y vacíos regulatorios; todas situaciones que permiten el desarrollo de prácticas que impiden la consolidación de un servicio de transporte que favorezca la movilidad de los y las ciudadanas que lo necesitan.

La realidad del AMM es particular, como la de todo territorio, y no constituye de manera exclusiva la suma de sus municipios. Por lo tanto, necesita de herramientas regulatorias propias a nivel metropolitano que favorezcan el trabajo articulado con lo provincial, con cada municipio que conforma el área en particular y con aquellos que no la conforman también. Asimismo, las particularidades sociales, culturales, espaciales, económicas de los municipios del AMM y por fuera de ésta, deben ser tenidas en cuenta.

Para la realización del trabajo de campo, dentro del AMM se seleccionó un barrio ubicado en la periferia, el Barrio Tamarindos (Figura 2), emplazado al noreste del departamento de Las Heras entre calle Independencia hacia el norte, Lateral Oeste Avenida Acceso Norte al este, calle Álvarez Condarco al oeste y calle Juan José Paso al sur. El mismo incluye tres loteos construidos en distintas etapas entre los años setenta y ochenta, Tamarindos 1, 2 y 3 . Este barrio de viviendas consolidadas de clase media se encuentra circunscripto por barrios populares de vivienda social y otros asentamientos informales que se fueron estableciendo en las últimas tres décadas como resultado de la expansión urbana espontánea del AMM, del crecimiento de la desigualdad social, de la ausencia de políticas públicas, del aumento de la necesidad y del terremoto del año 1985 , entre otras causas.

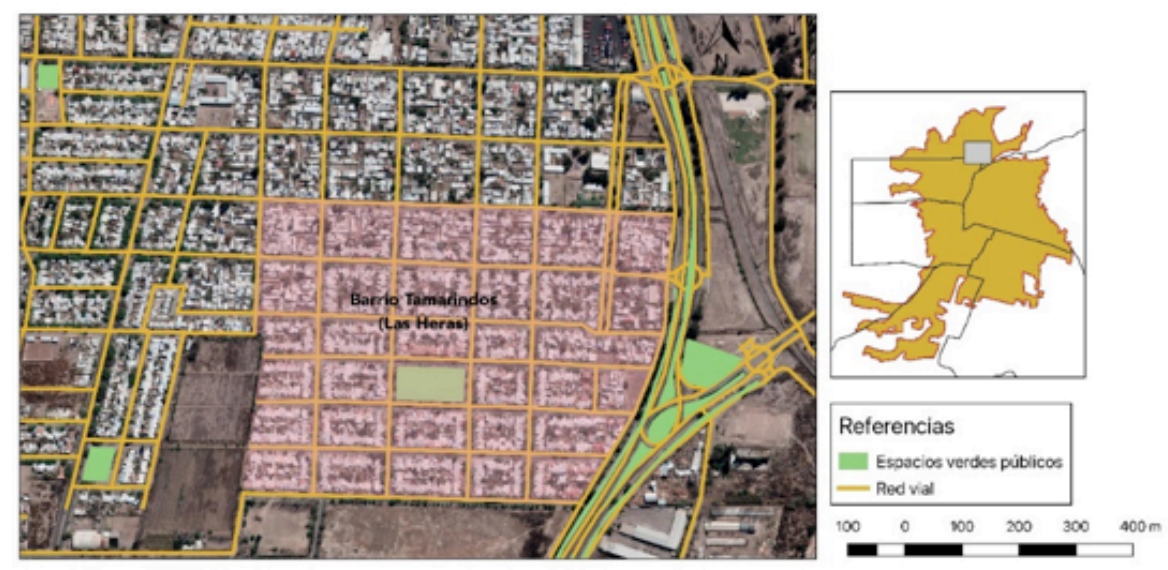

Figura 2. Barrio Tamarindos, departamento de Las Heras, AMM, Argentina. Fuente: elaboración propia, con la colaboración de Matías Ghilardi.

La elección del barrio dependió, por un lado, de su ubicación en la periferia del AMM, en una de las zonas más pobres de la aglomeración y más alejadas de la Capital hacia el norte; por otro lado, de su cercanía a la finalización de una de las líneas troncales del nuevo sistema de transporte público, la Línea 6, que conecta el departamento de Las Heras con la Capital de Mendoza; particularmente el recorrido 606 es el que vincula a ambos departamentos de forma más directa y rápida (Figura 3 ). 


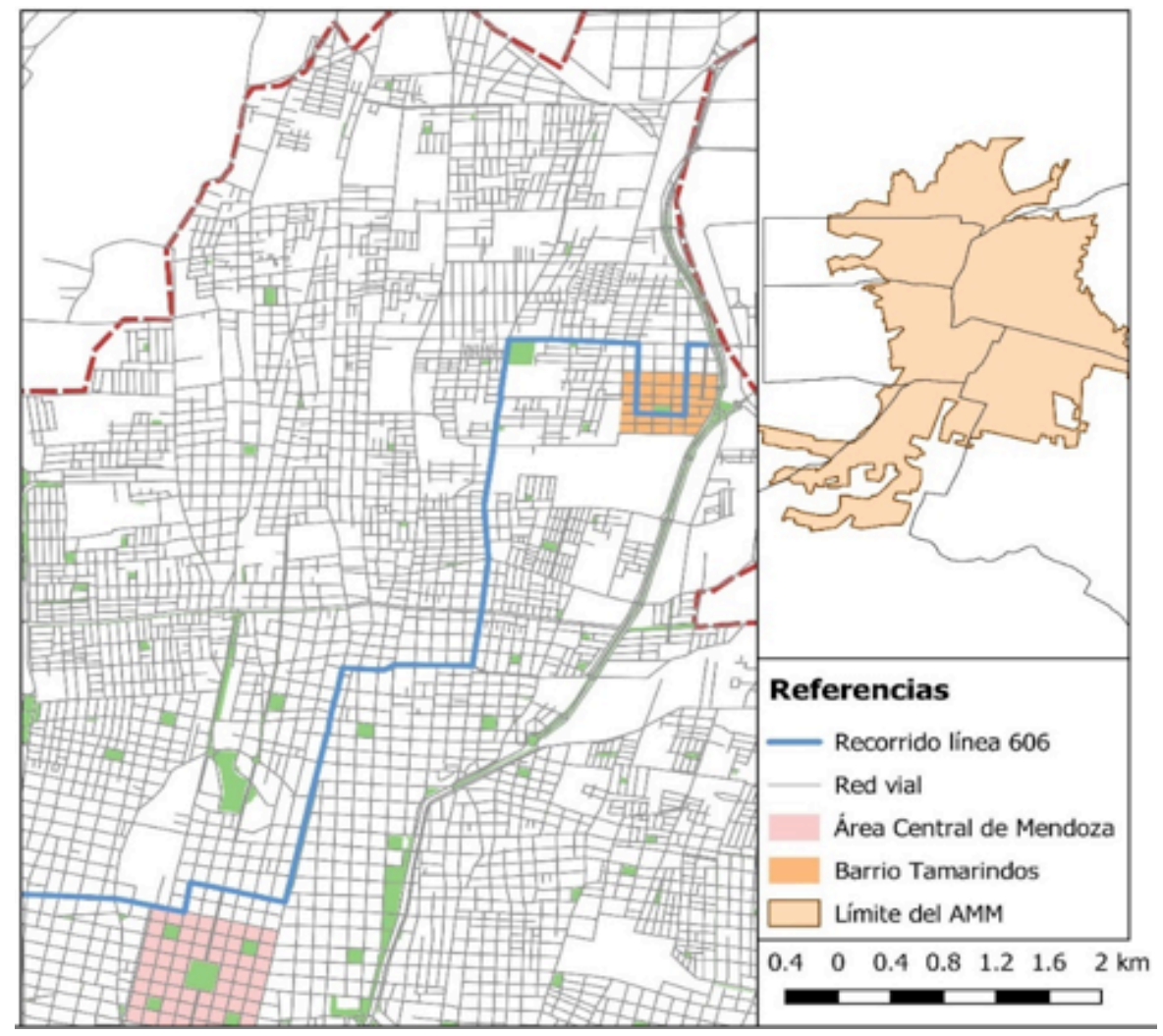

Figura 3. Red Línea 6 y accesibilidad del Barrio Tamarindos, departamento de Las Heras, AMM, Argentina. Fuente: elaboración propia con la colaboración de Matías Ghilardi.

\section{El sistema de transporte del AMM en las tres últimas décadas}

Con el regreso a la democracia, en el año 1985, la Dirección de Vías y Medios de Transporte de la Provincia de Mendoza comenzó un proceso de planificación de un nuevo sistema de transporte público de pasajeros de acuerdo con la Ley 4.305/78. Para ello se consultaron expertos y en el año 1986 se realizó una Encuesta de Origen-Destino. Hacia el año 1991 se inauguró un nuevo sistema de transporte público de pasajeros conformado por colectivos en su gran mayoría y por trolebuses en una pequeña proporción. El servicio de colectivos estaba en manos del sector privado mediante un proceso de licitación pública, mientras que el de trolebuses permanece en manos estatales desde los años 60 a la actualidad. Es importante destacar el fuerte financiamiento del Estado Nacional y Provincial al transporte por medio de subsidios a las empresas privadas prestadoras del servicio de más del 60\%, según datos de la Secretaría de Transporte de Mendoza y de la Secretaría de Transporte de la Nación para el año 2012 (Devito, García y Martínez, 2016).

Este nuevo sistema implementado en el año 1991 presentaba un carácter predominantemente radial dado que los servicios siempre llegaban al Centro de la Ciudad de Mendoza, área que nucleaba la gran mayoría de los viajes; prácticamente todas las líneas de colectivos y trolebuses tenían como destino final este centro del AMM. Existieron sólo algunos pocos recorridos que unían áreas periféricas sin ingresar al centro de la Ciudad, generando una fuerte congestión vehicular con las consecuencias sociales y ecológicas que eso significa.

Asimismo, el sistema privilegiaba los recorridos por las zonas de mayor densidad de población y la distribución de las frecuencias de los servicios se hacía de acuerdo con 
las horas de mayor demanda, coincidentes con los horarios de ingreso y salida de los establecimientos educativos de la Ciudad. Las unidades de transporte se veían saturadas de usuarios, lo cual daba cuenta de las limitaciones del servicio.

Este sistema no priorizó el transporte colectivo, público, por sobre el individual, privado, el automóvil -medio de movilidad predominante entre las clases medias y altas de la provincia-, y aumentó la oferta de estacionamiento sobre la calzada, así como la habilitación de playas de estacionamiento (Marsonet, 2011). El deficiente servicio de transporte brindado por las empresas privadas desalentó su uso, diversificó los medios de transporte utilizados y, alentó fuertemente el uso del automóvil. Al respecto una cita de Giner de Lara (2002:14) reafirma el proceso evidenciado de disminución en el uso del transporte público en el AMM:

Entre 1986 y 1998, los movimientos de los habitantes del Gran Mendoza se incrementaron $99 \%$ y se produjo una mayor diversificación en los medios de transporte utilizados, cayendo la participación relativa del transporte público de pasajeros desde un 50\% a un 30\%. Según cifras de la Encuesta Origen-Destino de 1998, de los 1.500.00o movimientos que se concretan diariamente sólo 500.000 se hacen usando transporte público de pasajeros.

Según la Encuesta Origen-Destino 1998 para el AMM, el traslado diario de la población a sus lugares de trabajo en la Capital se realizaba fundamentalmente en automóvil, trolebus o taxi/remis y no en colectivo (Lara, 2004).

El sistema de transporte vigente desde el año 1991 continuó con algunas diferencias hasta el 2018. Las grandes crisis económico-sociales y políticas sufridas por Argentina hacia mediados de la década del 90 y en el 2001/2002 afectaron la prestación del servicio que continuó deteriorándose junto con la falta de regulación y control por parte del Estado provincial.

Hacia el año 2005 se realizó un nuevo proceso licitatorio del servicio que concedió a empresas privadas el manejo del mismo hasta el año 2018. En un primer momento, la renovación de las concesiones derivó en nuevas unidades de colectivos, en un novedoso sistema de boleto prepago y en el pago a las empresas por parte del Gobierno por kilómetro recorrido, con el fin de incentivar el aumento de frecuencias disponibles hasta ese momento. Sin embargo, con el paso de los años las mejoras previstas no se lograron.

Así, la ausencia en la continuidad e integralidad de las políticas de transporte público a lo largo de los años en el AMM, generó un deterioro en la prestación del servicio; el aumento del uso del transporte individual, fundamentalmente entre las clases medias; graves problemas de superpoblación y congestión vehicular de los principales accesos, avenidas y calles céntricas; y también una clara falta de conectividad y cobertura de las líneas de transporte, la superposición de recorridos, la contaminación ambiental y el descontento entre la población.

En el año 2010 se realizó un nuevo operativo de la Encuesta Origen-Destino (EOD 2010) a partir del Proyecto de Transporte Urbano de Buenos Aires (PTUBA) que financió estudios en las áreas metropolitanas de diversas provincias argentinas para promover la formulación de estrategias integrales de planificación del transporte urbano en la búsqueda de una "movilidad eficiente, moderna y sustentable que responda a las necesidades de desplazamiento de toda la población" (Ministerio del Interior y Transporte, 2012:XVII). El objetivo principal buscado fue determinar cómo y por qué se movía la población residente de manera habitual en el AMM. 
La encuesta relevó un total de 14.615 personas, 4.055 hogares y 24.888 viajes de una población de 850.802 personas mayores de 3 años de edad. Los resultados indicaron que el 77,25\% de los y las encuestadas realizó viajes el día anterior a la medición, así como que predominaba el uso del colectivo con un $44,74 \%$ y le seguían los movimientos realizados en automóvil (como conductor/a y/o acompañante) en un 31,06\%. En tercer lugar, apareció el traslado a pie en el 16,19\% de los casos encuestados. En este punto, se detectó una clara diferencia de género en el uso de los medios de transporte. Las mujeres utilizaban fundamentalmente el colectivo, mientras los varones más el automóvil. También, se encontró un uso diferencial de los medios de transporte de acuerdo al nivel de ingreso. En cuanto a los motivos del traslado, el trabajo y las actividades educativas representaron casi el $68 \%$ de los viajes diarios, constituyendo la principal causa de la movilidad. Con relación a la duración de los traslados desde el lugar de origen al de destino, la encuesta reveló que cerca de la mitad de los viajes del AMM tenía una duración de hasta 20 minutos y sólo el 4,7\% se extendía por más de una hora. En cuanto a los itinerarios recorridos, la Capital concentraba el 27\% de los viajes totales diarios en todos los medios de transporte, siendo la primera generadora y atrayente de viajes, pero ocupaba el segundo lugar si se la relacionaba con cada uno de los departamentos del AMM, ya que la mayor magnitud de viajes se daba dentro de cada uno de estos (viajes intradepartamentales) (Ministerio del Interior y Transporte, 2012).

En marzo de 2017 el gobierno de Mendoza firmó un convenio vinculado a la movilidad urbana con los intendentes de los municipios que conforman el AMM y del municipio de Lavalle. El mismo buscó consensuar las diversas formas de movilidad ya existentes en los municipios en el marco del Plan Integral de Movilidad 2030 y según manifestó el gobierno permitiría "tener un sistema de transporte más eficaz y más eficiente en un concepto mucho más global como lo es la movilidad urbana" (Prensa Gobierno de Mendoza, 2017).

El Plan Integral de Movilidad Sustentable del Área Metropolitana del Gran Mendoza 2030 cuenta entre sus premisas: desarrollar una red de transporte público de calidad, adecuada a la demanda de viajes; desalentar el uso del transporte particular (automotor); favorecer la marcha a pie y la bicicleta; promover la ciudad compacta, de distancias cortas, con espacios públicos de calidad; y que el sistema de transporte haga un uso eficiente del espacio público.

Asimismo, en 2018 el gobierno de la provincia promulgó la nueva Ley de Movilidad 9.086 y el Decreto 1.512 que modifica algunos de sus artículos. Esta norma regula todo el transporte público de pasajeros de la provincia, incluidos colectivos, trolebuses, metrotranvías, taxis, remises y transportes escolares. El capítulo II, Artículo $4^{\circ}$ del Decreto sostiene que "el Servicio Público de Transporte de Pasajeros es aquel que tiene por objeto satisfacer las necesidades básicas de transporte de la sociedad y como tal es considerado estructurante del sistema". Más adelante continúa: "que le garanticen el acceso a un sistema de movilidad integral prestado en condiciones de calidad y eficiencia (...) continuo, económico, seguro y accesible" (Ministerio de Economía, Infraestructura y Energía, 2018); todas características deseables, pero no fáciles de lograr ni mantener sin una adecuada planificación, aplicación y control o seguimiento.

Es importante destacar que la nueva Ley de Movilidad remite a los lineamientos, directrices y programas que se enuncian al respecto en la Ley 8.999 del Plan Provincial de Ordenamiento Territorial, lo cual se considera muy importante en la búsqueda por articular las diversas políticas en el marco de un determinado territorio y, particularmente, tener presente los aspectos referidos a los procesos de regulación de la apropiación y uso de los espacios. En el capítulo IV, artículo 6, se afirma que el sistema de transporte deberá tener presente las características sociales y topográficas de cada territorio, 
(...) el uso de los factores de ocupación del suelo de acuerdo con lo normado por Ley № 8.999, el Plan Provincial de Ordenamiento Territorial, localización de actividades atractoras, equipamiento y servicios, densidades poblacionales, ubicación yjerarquía de redes viales, infraestructura social y comunitaria (Ministerio de Economía, Infraestructura y Energía, 2018).

Además, la norma aclara que la Secretaría de Servicios Públicos se encargará de la planificación y la regulación tarifaria, mientras que el Ente de la Movilidad Provincial (E.Mo.P) tendrá las facultades de control y fiscalización.

Finalmente, junto con la nueva Ley de Movilidad de la provincia, el miércoles 2 de enero último, se puso en vigencia el nuevo sistema de transporte público de pasajeros en el AMM, el llamado Mendotran. El anterior plan databa de 1991 y estaba pensado también para el AMM; sin embargo, este constituía un territorio muy distinto al que hoy se puede identificar y caracterizar luego de casi treinta años.

Actualmente, Mendoza -al igual que otras ciudades sudamericanas antes descriptas- se encuentra transitando grandes cambios en materia de transporte y movilidad urbana. En estas transformaciones el énfasis está puesto en la inclusión social, el desarrollo sostenible, la búsqueda de la vinculación entre sistema de transporte y planificación urbana, entre otros aspectos, según lo expresado por el gobierno de la provincia y los diversos municipios que integran el área urbana.

\section{El nuevo sistema de transporte público del AMM: el Mendotran}

El Mendotran consiste en un sistema intermodal o multimodal que prevé que el o la pasajera haga uso de diversos medios de transporte integrados, coordinados y conectados eficientemente para recorrer el AMM; incluye entonces, la interconexión del Gran Mendoza con el centro de la Ciudad o Capital a través de la combinación de distintos modos de movilidad urbana entre recorridos como son el metrotranvía, el trolebus, el colectivo, las ciclovías de bicicleta y el traslado a pie. Asimismo, da la posibilidad de realizar hasta dos trasbordos para llegar a destino durante 90 minutos a partir del primer viaje.

El sistema está organizado entre servicios troncales, interdepartamentales, locales o intradepartamentales y diferenciales (Figura 4). Es una red de transporte con recorridos troncales por carriles especiales que se dirigen de norte a sur y de este a oeste del AMM, como principales circuitos; el resto circula en sentido perpendicular a éstos (Jelvez, 2019). El sistema pretende interconectar los servicios del AMM con el Centro de la Ciudad y busca generar mejores tiempos de viaje y menor espera en el traslado de pasajeros en toda el área metropolitana. 


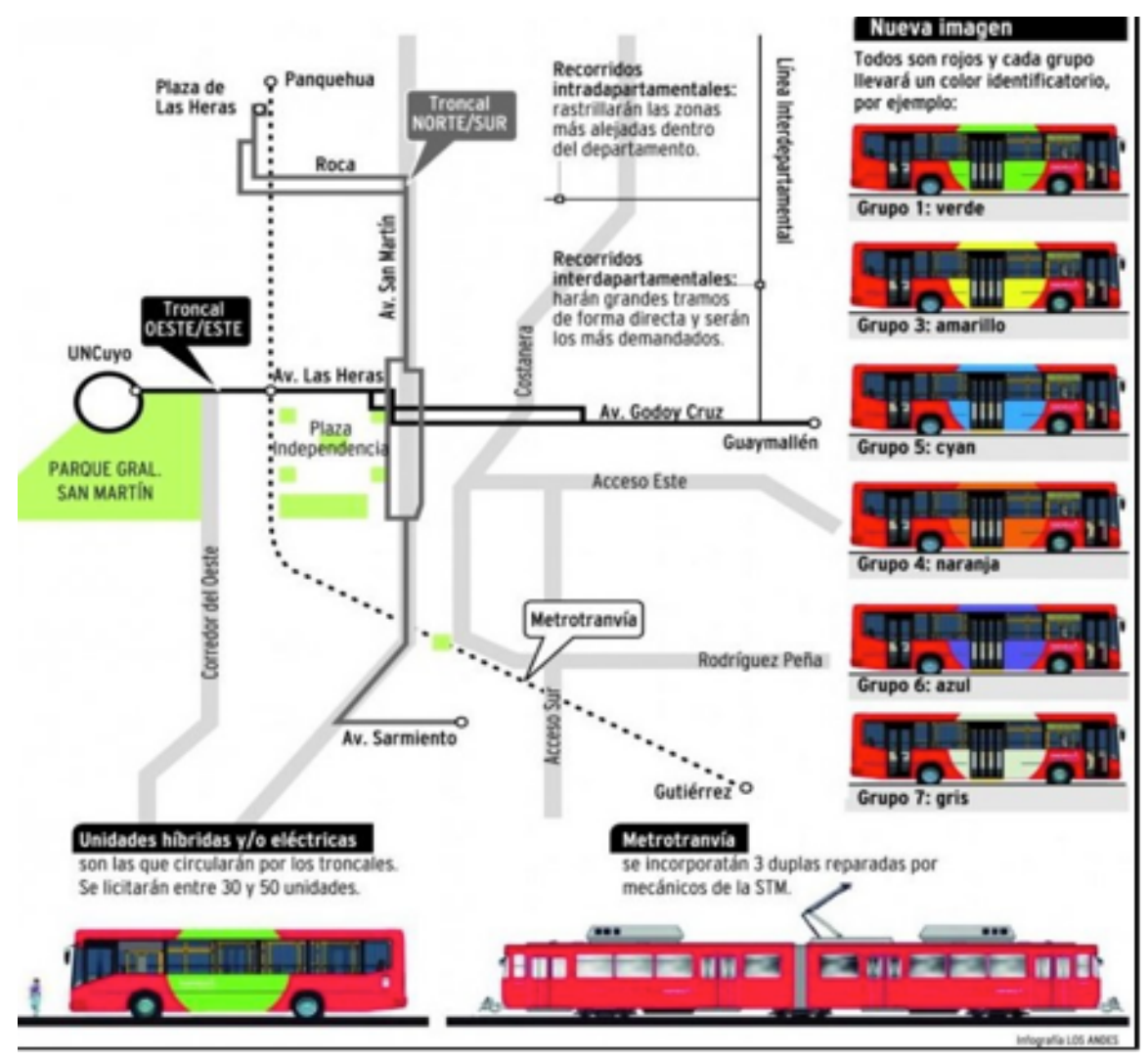

Figura 4. Sistema Mendotran 2019, AMM, Mendoza, Argentina. Identificación de las distintas formas de transporte. Fuente: Jelvez (2019).

El denominado sistema troncal estructurante significa un servicio de alta frecuencia y regularidad horaria cuyo principal objetivo es vincular los departamentos del AMM entre sí; sus recorridos transitan los grandes ejes de demanda de transporte (Norte-Sur y Este-Oeste). El mismo está conformado por ocho líneas de transporte de colectivos (varias de cuyas unidades son híbridas y/o eléctricas) que están organizadas por números y colores y presentan cierta área geográfica de cobertura. Además, cuenta con una línea de tranvía, llamado Metrotranvía (MTM) -sistema de transporte eléctrico que recorre el AMM de Norte a Sur-, y una línea de trolebús -medio de transporte eléctrico que data de 1958 en la provincia, ha sido usado de manera irregular en los últimos años y hoy sólo funciona en la línea Parque que une de oeste a este la Ciudad con el departamento de Guaymallén. 


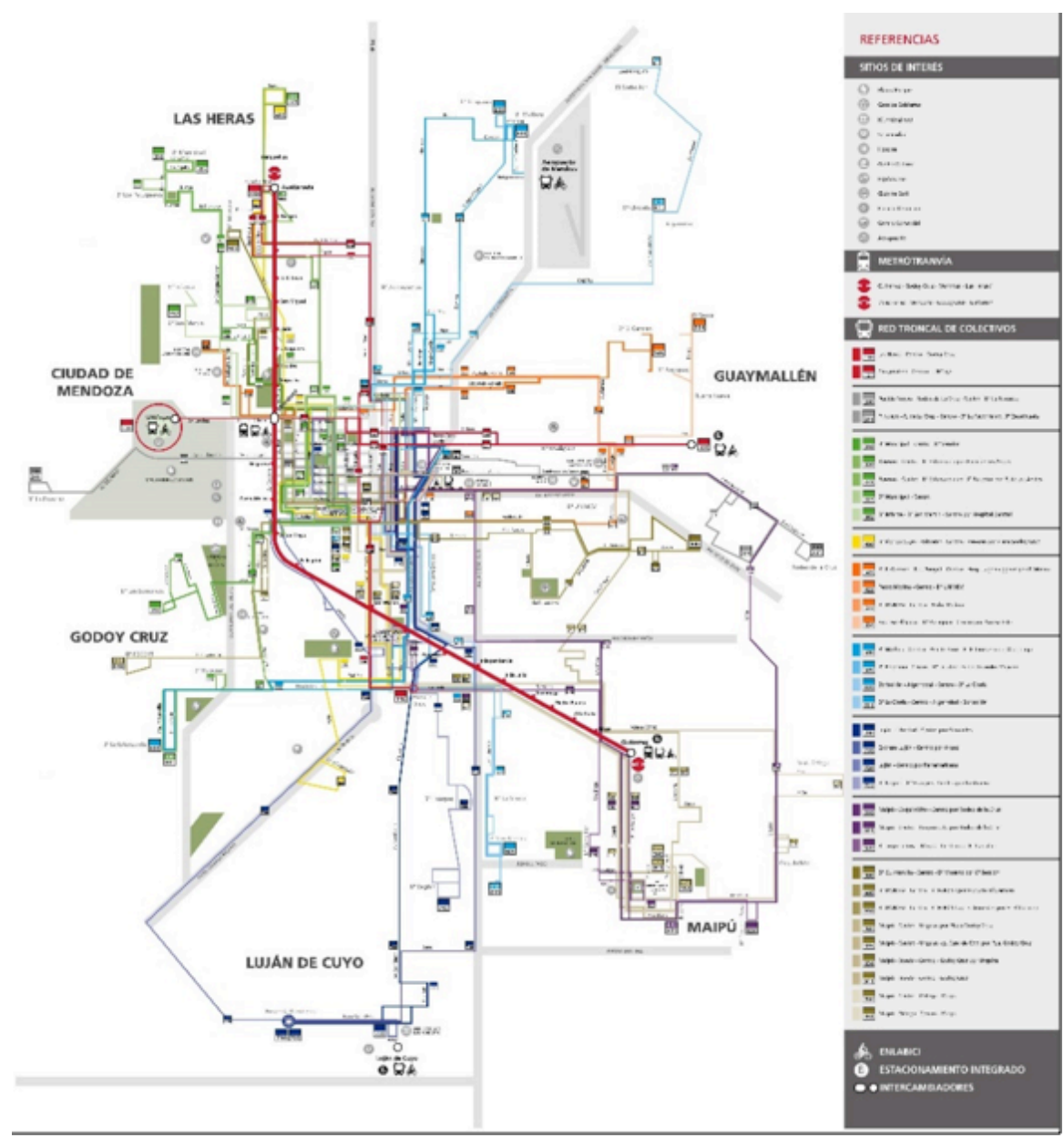

Figura 5. Mendotran, AMM, Mendoza, Argentina: recorridos troncales publicados 2019. Línea 6 identificada en color celeste, diseñada para vincular la aglomeración de norte a sur. Fuente: Secretaría de Servicios Públicos, Gobierno de Mendoza.

Por otro lado, se encuentran las rutas interdepartamentales que, como indica su nombre, prestan servicio de transporte entre los departamentos del AMM. Responden a movimientos masivos de personas y unen recorridos que no son cubiertos por las rutas troncales. A lo largo de su traza reciben pasajeros provenientes de recorridos locales y troncales que hacen trasbordos para llegar a sus destinos. Hay tres tipos de rutas interdepartamentales: la categoría 1 que vincula departamentos del AMM atravesando la Ciudad o Capital sin ingresar a la zona del microcentro (diametral o externos), la categoría 2 que vincula departamentos con la Ciudad (radial) y la categoría 3 que vincula departamentos sin pasar por la misma (que es novedosa respecto del anterior sistema de transporte). La categoría 2 es la que actualmente está siendo más desarrollada desde la implementación del sistema.

Los servicios locales de colectivos (alimentadores) vinculan zonas dentro de cada departamento (recorridos intradepartamentales); en algunos casos puede articularse con los servicios troncales o interdepartamentales. Este servicio busca vincular los lugares de origen con ciertos destinos locales (cabeceras departamentales, hospitales, etc.) o hasta puntos de transferencia con recorridos interdepartamentales o troncales para continuar el traslado hacia destinos fuera del departamento (Secretaría de Servicios Públicos, s/f). El mismo cuenta con menor frecuencia que el resto. 
Los servicios diferenciales presentan pocas paradas entre el punto de origen y el destino final, es por lo tanto un servicio más directo y al mismo tiempo, más caro. Busca atraer a usuarios de vehículos particulares y desalentar el uso de este medio individual de transporte al ofrecer viajes más cortos y con mayor confort. Se incluye servicios del departamento de Luján de Cuyo (puntualmente, la zona residencial de Chacras de Coria) y de Maipú a la Ciudad de Mendoza; ambos departamentos presentan la mayoría de los desarrollos inmobiliarios privados de clase media y alta del AMM. Por ello, se entiende que no es casual que el servicio se preste en esas zonas. También, existe un servicio que une el Aeropuerto, la Terminal de colectivos y la zona hotelera de la Capital, dado el importante flujo de turistas que requieren movilidad diariamente.

El nuevo sistema sigue contando mayormente con prestadores privados. De los ocho grupos de colectivos, siete siguen en manos de empresas que ya concesionaban el transporte desde 2005, última licitación pública realizada por el Gobierno de la provincia. La otra línea está en manos del Estado mediante la Sociedad de Transporte de Mendoza (STM) -ex Empresa Provincial de Transporte de Mendoza (EPTM)-, que supo operar las líneas de trolebuses y del Metrotranvía. "En total, las firmas disponen de una flota operativa diaria de 1.100 unidades aproximadamente en el área metropolitana" (Jelvez, 2019).

El automóvil convive con el Mendotran. Este constituye el medio de movilidad individual preferido entre las clases medias y altas en el AMM. Esta característica ya era notoria hacia inicios de los años 90 y se ha ido incrementando con el correr del tiempo. El mismo genera importantes problemas de congestión en la mayoría de las vías de acceso a la Capital como son el Corredor del Oeste, que vincula el AMM de norte a sur; el Acceso Este que la articula de este a oeste y el Acceso Sur que lo hace de sur a norte. También, las calles internas a la aglomeración se ven muy afectadas en las horas pico, lo cual genera dificultades de movilidad también para el resto de la población que se traslada en transporte público, bicicleta o a pie.

\section{El Mendotran y la movilidad: situación actual luego de su reciente implementación}

A partir del análisis del sistema de transporte desde su reciente implementación en enero pasado, se pueden detectar algunos elementos y caracterizarlos, así como identificar algunas tendencias y sacar algunas conclusiones preliminares. Es importante tener en cuenta que el sistema ha sufrido algunos cambios parciales, eminentemente coyunturales, a partir de su implementación en enero pasado, en función fundamentalmente de las quejas de la población usuaria. A continuación, se desarrollan algunos de los puntos que se consideran más importantes y que se han podido analizar desde los documentos consultados y las observaciones y las entrevistas en campo.

Un primer elemento observado es la desconexión existente entre la provincia que rige el sistema de trasporte público del AMM a partir de la Ley de Movilidad del 2018 y los municipios; es decir, el gobierno provincial administra y coordina el sistema de transporte del AMM sin la participación de los seis gobiernos municipales que conforman dicha Ciudad. Esto lleva a que particularidades y necesidades individuales municipales, además de conflictos intermunicipales y otras cuestiones, no puedan ser receptadas y tenidas en cuenta.

Otro desajuste se observa en el financiamiento del sistema, el cual es realizado con los ingresos de toda la provincia por medio de los subsidios a las empresas prestadoras y no exclusivamente con el dinero proveniente de los gobiernos municipales que integran el AMM, aun cuando sólo los y las residentes de este conglomerado hacen uso del transporte público casi con exclusividad. 
Por su parte, las empresas no son obligadas a realizar las inversiones que se supone deben hacer para mantener el funcionamiento y la prestación de sus servicios de manera eficiente. Además de que el subsidio es por $\mathrm{km}$ recorrido y no por número de pasajeros transportados; en consecuencia, a las empresas no les modifica su ganancia si los y las usuarias no hacen uso del transporte que brindan por diferentes motivos. La falta de inversión privada se observa en el estado de los colectivos, en la falta de mantenimiento y limpieza de los mismos y en la inexistencia en un gran número de unidades de las máquinas que cobran los boletos, lo cual impide la recaudación por parte del Estado.

Otro punto identificado es la falta de información y la deficiente comunicación realizada hacia la población antes de la implementación del sistema, así como luego de su puesta en marcha. Esto se explicita en la falta de cartelería y en errores u omisiones en la señalética en las calles y paradas de transporte, que se agrava aún más en determinados lugares más alejados de la Capital mendocina (Figura 6): información errónea y/o limitada, por ejemplo, en el detalle de los recorridos de las líneas, vuelve prácticamente imposible planificar el viaje y llegar a destino con éxito, incluso siendo un pasajero frecuente. Otro detalle es que parte de la información suele estar disponible -aunque no siempre actualizada- en plataformas digitales y redes sociales que pueden no ser accesibles para toda la población. De ahí que el uso de folletería en las calles, los puestos de información en lugares estratégicos de los barrios, los carteles detallados en las paradas antiguas de colectivos y en las nuevas con el recorrido completo por línea, entre otros recursos comunicacionales, serían esenciales para el conocimiento y entendimiento de todos los y las pasajeras, así como para evitar quejas hacia el sistema.

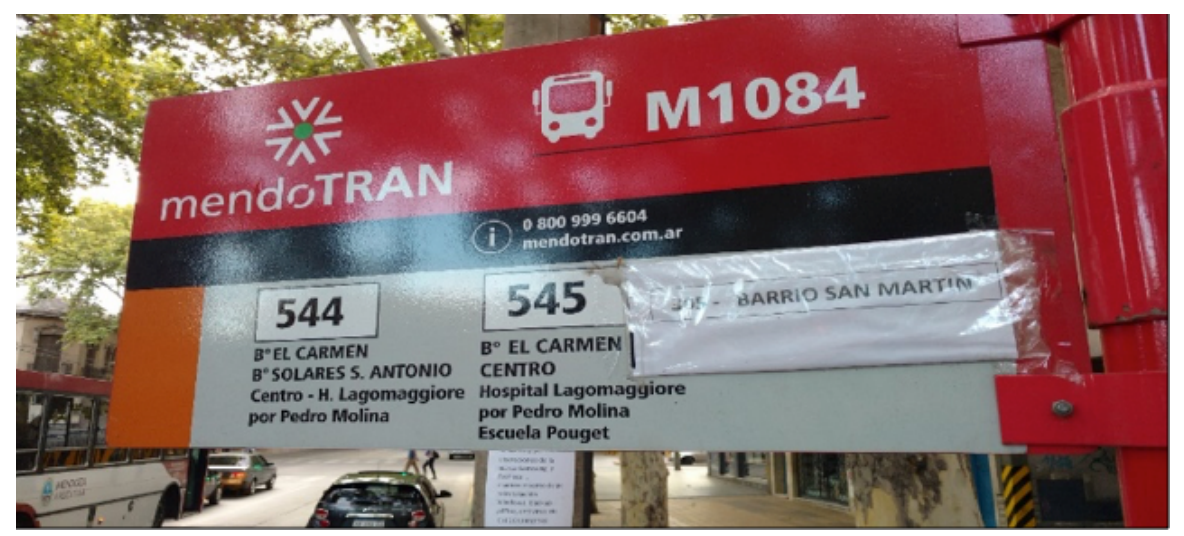

Figura 6. Cartel nuevo con rectificaciones de recorridos y detalle incompleto de los recorridos de cada línea, AMM. Fuente: fotografía propia tomada en trabajo de campo.

Otra cuestión muy recurrente entre la población entrevistada es la crítica a la frecuencia del servicio de transporte al inicio de la implementación. Las quejas recibidas hacia el gobierno han llevado a modificar y aumentar la frecuencia particularmente en horas pico en varias líneas de colectivos, lo cual no soluciona el problema porque colapsa las calles y dificulta la circulación generando más demoras.

De las entrevistas se rescata la disminución del tiempo de viaje desde los barrios más periféricos a la Capital de Mendoza; es decir, de los traslados por vías troncales. No obstante, existen reiteradas quejas respecto de la demora en general de las unidades, del tiempo de espera en las paradas y, en consecuencia, de la extensión total de los viajes, incluso debido a los distintos trasbordos y combinaciones que suponen. Es evidente que existe un desfase entre los horarios publicados y los reales debido, por un lado, a que la frecuencia de las unidades es informada de manera estática; es decir, se comunica 
el horario de salida del colectivo desde el inicio del recorrido, siendo que las empresas prestadoras -la mayoría de las veces- no pueden cumplir con los tiempos por diversas razones, de índole propia y ajena.

Asimismo, se dificulta mantener una frecuencia constante con la alta congestión vehicular existente en las calles del AMM, fundamentalmente a primera hora de la mañana, al mediodía y hacia la noche, coincidentemente con los ingresos y salidas de las escuelas y los trabajos de la mayoría de la población. Otro factor que puede incidir en la extensión de los recorridos son los cortes de calles por obras municipales o por manifestaciones. Se considera que este problema podría ser solucionado en gran parte con un sistema de GPS (Sistema de Posicionamiento Global) incorporado a cada unidad de transporte, que debería ser una inversión de las empresas, además de que permitiría planificar los viajes con mayor exactitud y disminuir los tiempos de espera. Parte del dinero recaudado por las empresas prestadoras podría destinarse a ello, si se cumplieran con las inversiones previstas por ley.

Por otro lado, se entiende que las demoras en los traslados pueden deberse a la falta de integración, articulación y coordinación que aún existe entre las distintas redes de transporte (troncales, intradepartamentales e interdepartamentales) y medios (colectivos y metrotranvía, fundamentalmente) que integran el nuevo sistema multimodal. En este tipo de sistemas que combinan movilidades es fundamental la planificación y el riguroso cumplimiento de cada una de las partes, ambos requisitos que no están siendo cumplidos en la actualidad.

Actualmente, se observa una pérdida en el sistema de la centralidad del trasbordo, siendo que constituía una de las novedades del Mendotran al momento de su puesta en marcha. En consecuencia, se multiplican los recorridos respecto del trazado original, se amplían en algunas zonas (fundamentalmente de los departamentos más alejados como Maipú, Las Heras y Luján de Cuyo) (Redacción ElNueve.com, 2019) y se superponen cada vez más, perdiéndose la importancia del trasbordo y aumentándose nuevamente el número de vehículos de transporte recorriendo las calles ya colapsadas de la ciudad. Este cambio se ha ido implementando paulatinamente, fundamentalmente en respuesta a las quejas arriba explicitadas respecto de la extensión en la duración de los viajes y de la falta de cobertura del sistema. La respuesta del gobierno ha sido el aumento en el número de colectivos, lo cual no garantiza que el sistema llegue a toda la población ni que lo haga eficientemente, en lugar de revisar la organización del sistema en su conjunto.

Asimismo, las esperas continúan realizándose sobre la calle, en los lugares de las tradicionales paradas de colectivos y/o en otros nuevos igual de inadmisibles. Esto genera varios problemas, en primer lugar, de seguridad para las personas; en segundo lugar, impide que el colectivo pueda detenerse cercano al cordón de la calle, congestionando el tránsito vehicular. La gran mayoría de estas paradas no permiten el resguardo ante el sol o la lluvia, e incluso son oscuras y peligrosas porque supone estar sobre la calle. No se han construido estaciones multimodales, entendidas como lugares de trasbordo, iluminados y equipados, pensados especialmente para el cambio de transporte en este tipo de sistemas multimodales.

Podrían edificarse centros de trasbordo dado que es necesario pensar en lugares exclusivos en los que las personas puedan cambiar de colectivo de manera segura (incluso áreas que permitan cambiar de medio de transporte, del colectivo al metrotranvía, al trolebús y/o a la bicicleta para promover la intermodalidad); espacios que estén iluminados, en los que no entren autos, con lugar para sentarse y seguridad para permanecer y transitar. Serían áreas no necesariamente grandes ni centrales, sino pericentrales; es decir, cercanas a los centros municipales, pero no en estos mismos para evitar la congestión 
vehicular. Los distintos departamentos del AMM cuentan con terrenos desocupados -que constituyen en sí mismo un peligro a la seguridad- que podrían destinarse a este uso sin grandes inversiones.

Otro elemento rescatado de las entrevistas es el elevado costo del boleto y el hecho de que la nueva tarifa no es diferencial entre recorridos como en el anterior sistema, sino plana; es decir, una única tarifa sea cual sea el recorrido que se haga dentro de determinada zona. Esto encarece mucho el traslado, más allá de la posibilidad del trasbordo con el mismo boleto durante el lapso de una hora. El trasbordo es un elemento aún no muy usado en el AMM, fundamentalmente por las deficiencias en su implementación como la falta de coordinación del sistema en su conjunto que limita su uso y extiende los tiempos de viaje.

Respecto del boleto, el Mendotran fue inaugurado junto con un importante aumento del viaje del $63 \%$ por decreto del gobierno provincial. El mismo pasó de $\$ 11$ a $\$ 18$. Este alto valor permite afirmar junto a Cebollada y Avellaneda (2008) que el nuevo sistema de transporte no puede ser considerado eficiente, porque no permite la movilidad de un conjunto importante de ciudadanos y ciudadanas de Mendoza para quienes el aumento del boleto les excluye de su derecho a la movilidad cotidiana y a la producción de la ciudad en la que habitan.

También, se destacan cuestiones vinculadas a las distintas líneas de colectivos. Las líneas troncales sufrieron varios cambios de recorrido en respuesta a las quejas de pasajeros y pasajeras por un servicio que verdaderamente sirviera de vinculación segura. Puntualmente, en el Barrio Tamarindos del departamento de Las Heras, con el cambio del sistema de transporte, las líneas de colectivos dejaron de ingresar a la urbanización y se dispusieron dos líneas troncales que la unían con la Capital del AMM (líneas 600 y 601). Los y las vecinas se quejaron de las modificaciones realizadas sin consulta previa y pidieron que las líneas ingresaran nuevamente al barrio dado que los problemas de inseguridad de la zona limitan la posibilidad de movilidad. Así, actualmente las dos líneas inicialmente diseñadas para comunicar la zona con el centro de la Ciudad fueron derivadas por otras áreas del departamento de Las Heras y se dispuso una nueva línea -la línea 606 (ver Figura 3)- que ingresa al barrio y acerca un poco más las paradas a la comunidad y ayuda a su traslado más seguro. Esta solución no es tal dado que, como se afirmó anteriormente, desde la implementación del nuevo servicio, se han aumentado las líneas de colectivos y las unidades que circulan por las calles, lo que congestiona cada vez más el servicio, al mismo tiempo que el problema de la movilidad es resuelto sólo coyunturalmente.

La Capital del AMM sigue siendo el segundo foco de atracción de los viajes, lo cual da cuenta de la importancia de las líneas troncales que buscan conectarla con el resto de los departamentos de la aglomeración. Sin embargo, existe un importante desconocimiento entre la población respecto de los nuevos trazados interdepartamentales, algunos de los cuales desaparecieron y otros fueron cambiados sin aviso con la implementación del nuevo sistema. En consecuencia, aparece la necesidad de movilizarse por otros medios, principalmente caminando, incluso con el problema de inseguridad que se vive en varias zonas del AMM. Los traslados a determinados lugares y horarios se vuelven peligrosos y hasta desaconsejables, fundamentalmente para los más jóvenes y mayores y para las mujeres, que constituyen los grupos más vulnerables en sus traslados en las ciudades. Algunos puntos identificados como los más difíciles de acceder por parte de los y las usuarias, fueron los hospitales públicos; puntualmente, el Hospital infantil Humberto Notti ubicado en el departamento de Guaymallén y el Hospital maternoinfantil Lagomaggiore de la Capital de Mendoza, ambos ubicados hacia el sudeste y el suroeste respectivamente del Barrio Tamarindos. 


\section{Consideraciones finales}

La investigación se inició con una serie de preguntas referidas al nuevo sistema de transporte público del AMM y su articulación con el proceso de movilidad cotidiana que allí sucede. Se partió del supuesto de que este nuevo servicio sostiene formas desiguales de movilidad que no contribuyen a habilitar prácticas más colectivas de construcción cotidiana de la ciudad. Además, se consideró que la movilidad es condicionante del derecho a la ciudad, de ahí la centralidad de su estudio. Entonces, se avanzó en las discusiones acerca del modo en que se puede asegurar el derecho a la movilidad cotidiana de toda la población a partir del servicio de transporte público, estrechando las distancias sociales y ampliando derechos vulnerados.

Se pudo conocer que el proceso de transformación del sistema de transporte urbano que vive el AMM, más allá de sus particularidades, comparte características fundamentales con otras reformas realizadas en gran parte de las ciudades más importantes de América del Sur a partir del cambio del nuevo milenio. Su objetivo es tender hacia la integración de las periferias urbanas mediante sistemas multimodales de movilidad.

El análisis del Mendotran permitió concluir que actualmente se debilita la idea de ciudad como construcción social, colectiva, y se profundiza un proceso contrario de segregación de una parte importante de la población mendocina en sus barrios periféricos; proceso iniciado desde el anterior sistema de transporte. Queda así aislada de los procesos de construcción y reconstrucción cotidianos de la ciudad que habita. Esta situación trae aparejado un proceso de fronterización intra ciudad que lleva a la conformación de variados territorios; un "modelo de ciudad de fronteras" (Márquez, 2003), marcada por una ciudadanía privada y una comunidad fragmentada en el que el derecho a la ciudad es sólo para algunas clases. La reforma del sistema de transporte en el AMM era una oportunidad importante para revertir esta tendencia, sin embargo, no se está logrando. Por ello, es importante continuar su indagación para identificar posibles soluciones que se traduzcan en la ciudad y sus habitantes.

Otro de los hallazgos del trabajo realizado ha sido recuperar algunas de las primeras impresiones de parte de la población usuaria del Mendotran, compararlo con el sistema de transporte anterior y así dar cuenta de algunas de sus debilidades e inconsistencias para pensar estrategias que permitan su mejora en un futuro próximo. Así, un punto central identificado es un problema que persiste del sistema anterior vinculado con la falta de coordinación institucional tanto al interior de la ciudad como hacia el exterior. Esto atenta contra la posibilidad de brindar soluciones integrales a la movilidad urbana. Entonces, los intentos de trabajo conjunto entre los municipios del AMM y por fuera de ésta (algunos ya iniciados), son fundamentales y deberían profundizarse. Asimismo, el Mendotran continúa siendo un sistema radial, con su centro en la Capital de Mendoza, que deja a parte de la periferia con pocas posibilidades de conexión.

Por otro lado, su implementación con grandes debilidades hasta el momento, fundamentalmente de frecuencia, accesibilidad y calidad, lleva a que el sistema de transporte público continúe siendo de uso exclusivo de la misma clase social, aquella que no tiene otra opción para movilizarse por la ciudad. Estos residentes de barrios de la periferia del AMM, se ven obligados a usar el Mendotran para movilizarse, siempre que puedan pagarlo, más allá de que este siga brindando un servicio deficiente y limitado. Así también es su posibilidad de movilizarse y transitar por la ciudad y de vivirla individual y colectivamente. Se puede afirmar entonces que el Estado, mediante sus políticas de transporte, no asegura el derecho a la ciudad.

En un mismo sentido, se observa con preocupación que frente a la imposibilidad de traslado de parte de la población que habita los lugares más vulnerables y periféricos del 
AMM, el nuevo sistema brinde un servicio diferencial hacia determinadas áreas ricas de la ciudad, como aquellas residenciales de los departamentos de Maipú y Luján de Cuyo.

El nuevo sistema de transporte busca desalentar el uso del automóvil entre las clases medias y altas; no obstante, este objetivo no será alcanzado si se mantienen las deficiencias actuales, tales como: falta de planificación y previsión con que el Mendotran ha sido puesto en marcha; escasa información brindada sobre características del nuevo sistema, horarios y tipos de servicios, recorridos; inexistentes y/o precarios lugares reservados a las paradas; impuntualidad; falta de mantenimiento de gran parte de las unidades (suciedad, excesivo ruido, etc.); maltrato de choferes hacia pasajeros y pasajeras, según expresan los y las informantes. Todas estas características favorecen a que el transporte individual siga siendo una mejor opción de traslado por la ciudad, incluso teniendo en cuenta el aumento sostenido del precio del combustible en Argentina en los últimos cuatro años.

Por todo lo expuesto, se considera que existe una distancia importante entre el diseño de la última política de transporte urbano en el AMM y su implementación; entre los puntos destacados por ejemplo en el Plan Integral de Movilidad Sustentable del AMM 2030 (promover la ciudad compacta, con espacios públicos de calidad, con un sistema de transporte que haga un uso eficiente del espacio público, etc.) y las prácticas estatales llevadas adelante para su concreción.

En primer lugar, es fundamental que todo sistema de transporte sea planificado y pensado junto con las transformaciones sociales y territoriales que se van evidenciando y, por ende, con otras políticas vigentes en la provincia. De ninguna manera puede concebírselo de manera aislada si se entiende al AMM como complejos territorios conviviendo. Al tomarse decisiones y hacerse reformas, en gran parte de manera abstracta, sin tener en cuenta las particularidades, problemáticas y complejidades territoriales así como las necesidades, representaciones y deseos de la población, el sistema termina generando situaciones no pensadas e incluso no buscadas, que se traducen en la segregación de parte de los y las usuarias: medios de transporte que no llegan a lugares cotidianos ni en horarios necesarios, otros que llegan a destinos que no son los usados o que son considerados difíciles y/o peligrosos de acceder, etc.

En segundo lugar, en todo proceso de transformación del transporte público es muy importante contar con las distintas perspectivas de quienes habitan la Ciudad, ya que toda obra de este tipo repercutirá en sus ciudadanos y ciudadanas; sin embargo, esto no fue promulgado por sus responsables. El AMM es compleja y presenta distinciones en su interior que deberían tenerse presentes al momento de diseñar y aplicar cualquier política pública. A su vez, este conocimiento y comprensión de la complejidad de los territorios urbanos es imposible de lograr sin una participación social activa desde el inicio; es decir, son indispensables las opiniones de los y las usuarias del sistema de transporte y de quienes se espera poder convencer de su uso.

Tercero, es central el rol del Estado como contralor de las empresas prestadoras del servicio, lo cual constituye la única herramienta disponible para regular el cumplimiento de sus obligaciones; fundamentalmente, aquellas relacionadas con las inversiones necesarias para la compra y mantenimiento de las unidades, control de sus empleados, cumplimiento de recorridos y frecuencias. La continuidad de las concesiones del Mendotran a las mismas empresas que hace años lo brindan de manera ineficiente, hacen dudar de la posibilidad real de que los controles estatales sean aplicados y de que estos agentes privados cumplan con sus obligaciones, cosa que en términos generales no ha sucedido a lo largo del tiempo. Ellos han sido siempre los únicos beneficiados, nunca la población con derecho a movilizarse por su ciudad. 
Cuarto, todo sistema de transporte público debería asegurar el derecho a la movilidad cotidiana por igual de los agentes sociales, independientemente de sus condiciones de clase, género, etnia o generación. Entonces, es central contar con un sistema de transporte eficiente que sea usado por toda la población; que sea accesible en un triple sentido, desde una suficiente cobertura territorial que permita trasladarse por toda la ciudad, hasta que esté disponible durante todo el día y que sea económicamente razonable. Un sistema que -como dice el Decreto 1.512 (Ministerio de Economía, Infraestructura y Energía, 2018)- garantice movilidad en condiciones de calidad y eficiencia. Sin embargo, no hay que perder de vista las particularidades de los agentes sociales y allí el Estado es el encargado de regular en ese sentido. Esto ayudaría a la inclusión, al encuentro en la ciudad, a ésta como producto social y no como resultado de algunos pocos que logran transitarla y vivirla individualmente. De esta manera, se acortarían las distancias sociales y se debilitarían las situaciones de segregación. Se coincide con Gutiérrez (2010:5) cuando afirma que "La movilidad permite el (re)encuentro (...) habilita la construcción de confianza. (...) es una herramienta para articular el territorio y también para su (re)composición y la de los espacios de vida".

Ello se considera importante en tiempos en los que el área de estudio del presente artículo se encuentra fuertemente fragmentada, parte importante de su población en crecida segregación y sus espacios de encuentro son cada vez más escasos e infrecuentes. Es fundamental el papel del Estado para desarrollar la infraestructura de transporte público necesaria que tienda a eliminar las fracturas evidentes al interior de la ciudad y no afianzar las distancias entre las islas de pobreza y de riqueza que la caracterizan. Cuando el sistema de transporte no llega a las personas que habitan en los territorios periféricos de la ciudad, "la sensación de marginalidad respecto al resto de la ciudad; el síntoma de la insularidad (...) parece incrementarse" (Avellaneda y Lazo, 2011:54) y reina el desconocimiento, la desconfianza y la inseguridad. 


\section{Bibliografía}

》 Avellaneda, P. y Lazo, A. (2011). Aproximación a la movilidad cotidiana en la periferia pobre de dos ciudades latinoamericanas. Los casos de Lima y Santiago de Chile. Revista Transporte y Territorio 4, 47-58.

»Barbosa, M. C.; Marre, M. y Martínez, L. (2016). Transporte Público y Ordenamiento Territorial. Una nueva regulación y articulación metropolitana para el Gran Mendoza. Proyección X, 7-21.

»Benedetti, A. (2007). Territorialidad y Fronteras en las relaciones sociales. Algunos conceptos ordenadores. Buenos Aires: Facultad de Filosofía y Letras, UBA.

»Benedetti, A. (2011). Territorio: concepto integrador de la geografía contemporánea. En P. Souto (coord.). Territorio, lugar, paisaje. Prácticas y conceptos básicos en geografía. Buenos Aires: FFyL, UBA.

»Benedetti, A. (2017). Perspectivas teóricas en el estudio de las fronteras estatales desde la geografía. En S. Braticevich; C. Tommei, y A. Rascován (comps.). Bordes, límites, frentes e interfaces. Algunos aportes sobre la cuestión de las fronteras (pp. 83-102). Buenos Aires: UBA.

»Cebollada, A. y Avellaneda, P. (2008). Equidad social en movilidad: reflexiones en torno a los casos de Barcelona y Lima. Scripta Nova 47 (270), 1-15.

»Dalla Torre, J. y Ghilardi, M. (2018). Situaciones de segregación y fronteras simbólicas intraurbanas en el Área Metropolitana de Mendoza, En E. Salizzi (comp). Fronteras en perspectiva, perspectivas sobre las fronteras. Buenos Aires: Editorial Facultad de Filosofía y Letras, UBA.

»Devito, L.; García Schilardi, M. E. y Martínez, L. (2016). Movilidad urbana sostenible: tres dimensiones de abordaje. En J. Dmuchowsky (coord.). Mobilitas II (pp. 41-58). Buenos Aires: Facultad de Arquitectura, Diseño y Urbanismo, UBA.

"García Schilardi, M. E. (2014). Transporte público colectivo: su rol en los procesos de inclusión social. Revista Bitácora Urbano Territorial 24 (1), 1-20.

" Ghilardi, M. (2017). Cercanía espacial y desigualdad social: las fronteras urbanas en el Área Metropolitana de Mendoza. En S. Braticevic, C. Tommei, y S. Rascovan, (comps.). Bordes, límites, frentes e interfaces: algunos aportes sobre la cuestión de las fronteras (pp. 230-246). Buenos Aires: UBA.

»Giner de Lara, E. (2002). Los medios de transporte en el Gran Mendoza. Revista Kairos, 1-15. Disponible en http://www.revistakairos.org/wp-content/uploads/ giner-de-lara.pdf

»Gutiérrez, A. (2005). Transporte público y exclusión social. Reflexiones para una Discusión en Latinoamérica tras la década del '90. XIII Congreso Latinoamericano de Transporte Público y Urbano. Lima.

" Gutiérrez, A. (2010). Movilidad, transporte y acceso: una renovación aplicada al ordenamiento territorial. Scripta Nova 86 (331).

» Gutiérrez, A. (2012). ¿Qué es la movilidad? Elementos para (re) construir las definiciones básicas del campo del transporte. Bitácora 21 (2), 61-74.

»Gutiérrez, A. y Rearte, J. (2007). Segregación y accesibilidad a servicios públicos de transporte en la Ciudad de Buenos Aires. Realidad Económica 228, 53-74. 
» Janoschka, M. (2006). El modelo de ciudad latinoamericana. Privatización y fragmentación del espacio urbano de Buenos Aires: el caso Nordelta. En M. Welch (ed.). Buenos Aires a la deriva. Transformaciones urbanas recientes (pp. 8o117). Buenos Aires: Biblos.

» Jouffe, I. y Lazo, A. (2010). Las prácticas cotidianas frente a los dispositivos de la movilidad. Aproximación política a la movilidad cotidiana de las poblaciones pobres periurbanas de Santiago de Chile. EURE, 36(108), 29-47.

»Landon, P. (2013). Movilidad cotidiana y exclusión social: anverso y reverso de la instalación de la autopista acceso sur en la periferia pobre de la metrópolis de Santiago de Chile. $3^{\circ}$ EIMUS, Encuentro Iberoamericano de Movilidad Urbana Sostenible. Lima, Perú.

»Lara, M. I. (2004). Un enfoque microeconométrico de los determinantes de la elección del modo de transporte: el caso del Gran Mendoza. Revista de la Facultad de Ciencias Económicas 2003, $105-126$.

»Lazo, A. (2008). Transporte, movilidad y exclusión. El caso de Transantiago en Chile. Scripta Nova, 270 (45), 1-5.

"Lizárraga Mollinedo, C. (2006). Movilidad urbana sostenible: un reto para las ciudades del siglo XXI. Economía, Sociedad y Territorio VI (22), 1-35.

" Marre, M.; Barbosa, M. C.; Martínez, L. (2015). Éxitos y desafíos en política de transporte público. Análisis comparativo de las innovaciones en la prestación del servicio de transporte público de pasajeros en las ciudades de Curitiba, Brasil; Santiago de Chile, Chile y Rosario, Argentina. Cuadernos de Cátedra 1, 89-111.

" Marsonet, P. (2011). El servicio público del transporte de pasajeros de Mendoza. Resultados socio-económicos de la desregulación en la década del 9o. Plataforma de Información para Políticas Públicas, Universidad Nacional de Cuyo, pp. 14. Recuperado de http://www.politicaspublicas.uncu.edu.ar/articulos/index/ el-servicio-publico-del-transporte-de-pasajeros-de-mendoza-resultadossocio-economicos-de-la-desregulacion-del-servicio-en-la-decada-del-9o (08/04/2019).

»Moreno Luna, C. A. (2016). Segregación en el espacio urbano de Soacha ¿Transmilenio como herramienta integradora? Revista de Arquitectura, 18(1), 48-55.

" Moreno Luna, C. A., y Rubiano Brínez, M. (2014). Segregación residencial y movilidad cotidiana en el contexto metropolitano. Un estudio a partir de las relaciones Bogotá-Soacha. Territorios 31, 133-162.

»Ortiz, F. y Spirtu, N. (2012). El Metrobus en la Avenida 9 de Julio: mejoras vs. Soluciones. Otra oportunidad desaprovechada. Revista Transporte y Territorio 9, 201-206.

»Rey, C. y Parras, M. (2012). Procedencia de la información en estudios de movilidad de la población a través de experiencias con aplicación de metodología cuantitativa y cualitativa. Resistencia-Chaco. Revista Transporte y Territorio 7, 100-118.

»Roa, H.; Rojas, C.; Carrasco, J. A. y Tudela, A. (2013). Movilidad urbana e indicadores de exclusión social del sistema de transporte: evidencia en una ciudad intermedia chilena. Revista Transporte y Territorio 8, 45-64.

» Segura, R. (2012). Elementos para una crítica de la noción de segregación residencial socio-económica: desigualdades, desplazamientos e interacciones en la periferia de La Plata. Quid 16 (2), 106-132. 
»Segura, R. (2013). Los pliegues en la experiencia urbana de la segregación socioespacial. Análisis comparativo de dos etnografías urbanas. En M. Carman, N. V. da Cunha y R. Segura (coords.). Segregación y diferencia en la ciudad (143-170). Ecuador: FLACSO-CLACSO-Ministerio de Desarrollo Urbano y Vivienda.

"Sheller, M., y Urry, J. (2006). The new mobilities paradigm. Environment and Planning A: Economy and Space, 38(2), 207-226.

"Soldano, D. (2013). Confinamientos, movilidad e intercambios Una investigación sobre las condiciones y los modos de vida en la periferia del Gran Buenos Aires. En M. Carman, N. V. da Cunha y R. Segura (coords.). Segregación y diferencia en la ciudad (83-119). Ecuador: FLACSO-CLACSO-Ministerio de Desarrollo Urbano y Vivienda.

»Vecchio, G. (2018). Urban mobility as human capability. Bridging the gap between transport planning and individual opportunities. Tesis Doctoral en Planificación Urbana, Diseño y Política, Politecnico di Milano.

»Vecchio, G. (2019). Movilidades periféricas en Bogotá: hacia un nuevo paradigma. Quid 16(10), 182-209.

»Vidal-Koppman, S. (2007). La expansión de la periferia metropolitana de Buenos Aires. Villas miseria y countries: de la ghettización a la integración de actores en el desarrollo local urbano. Scripta Nova XI (245).

\section{Otras fuentes consultadas}

»Desarrollo Urbano y Transporte, Gobierno de la Ciudad Autónoma de Buenos Aires (s/f a). Movilidad. CABA: Buenos Aires Ciudad. Recuperado de https:// www.buenosaires.gob.ar/desarrollourbano/transporte (1/3/2019).

»Desarrollo Urbano y Transporte, Gobierno de la Ciudad Autónoma de Buenos Aires ( $s / f b$ ). Beneficios Red Metrobus CABA. CABA: Buenos Aires Ciudad. Recuperado de https://www.buenosaires.gob.ar/movilidad/metrobus/ servicios-del-metrobus (1/3(2019).

» RES (2011). Curitiba, referente en movilidad ecointeligente. Eco Inteligencia. Recuperado de https://www.ecointeligencia.com/ (10/9/2019)

" INDEC, Gobierno de la Nación (2010). Argentina: Censo Nacional de Población, Hogares y Vivienda, Instituto Nacional de Estadísticas y Censos.

» Jelvez, M. (2019, enero 31). Mendoza: ¿Qué es el Mendotran y por qué genera polémica? El Destape Web. Recuperado de https://www.eldestapeweb.com/ mendoza/mendoza-que-es-el-Mendotran-y-que-genera-polemica-n55429 (01/3/2019).

" Ministerio de Economía, Infraestructura y Energía, Gobierno de Mendoza (2018). Ley № 9.086, Ley de Movilidad Provincial. Mendoza: Boletín Oficial. Recuperado de http://www.gobierno.mendoza.gov.ar/wp-content/uploads/ sites/19/2018/10/Ley-de-Movilidad-N\%C2\%BA-9086.pdf (20/2/2019).

" Ministerio de Economía, Infraestructura y Energía, Gobierno de Mendoza (2018). Decreto №1.512. Mendoza: Boletín Oficial. Recuperado de https://losandes. com.ar/uploads/2018/og/ley-movilidad5b9f82ce7c62b.pdf (20/2/2019).

" Ministerio de Transporte, Gobierno de la Nación Argentina. Encuesta OrigenDestino 2010. Argentina: Argentina.gob.ar. Recuperado de https://www. argentina.gob.ar/transporte/dgppse/publicaciones/encuestas (1/3/2019). 
» Ministerio del Interior y Transporte, Proyecto de Transporte Urbano de Buenos Aires, Presidencia de la Nación (2012): Encuesta origen-destino 2010: Movilidad en el Área Metropolitana de Mendoza. Argentina: Argentina.gob.ar. Recuperado de https://www.argentina.gob.ar/transporte/dgppse/publicaciones/encuestas (22/2/2019).

"Prensa Gobierno de Mendoza (2017). Mendoza: Unicipio: Cornejo firmó un acuerdo para la movilidad sustentable del Área Metropolitana. Recuperado de http://www.prensa.mendoza.gov.ar/unicipio-cornejo-firmo-un-acuerdo-parala-movilidad-sustentable-del-area-metropolitana/ (01/4/2019).

»Redacción (2018, diciembre 27). El 2 de enero aumenta el boleto de colectivo en Mendoza y costará 18 pesos. Diario Los Andes. Recuperado de https://losandes. com.ar/article/view?slug=el-2-de-enero-aumento-el-boleto-de-colectivo-enmendoza-y-costara-18-pesos (10/3/2019).

»Redacción ElNueve.com (2019, abril 8). Mendotran: Ampliaron Recorridos en el Gran Mendoza. El Nueve.com. Recuperado de https://www.elnueve.com/ mendotran-ampliaron-recorridos-en-el-gran-mendoza (12/4/2019).

"Secretaría de Ambiente y Ordenamiento Territorial, Gobierno de Mendoza (2017). Plan Provincial de Ordenamiento Territorial Ley N8.999. Mendoza: Mendoza Gobierno. Recuperado de https://www.legislaturamendoza.gov. ar/wp-content/uploads/2017/12/4_8999_plan_ordenamiento_territorial.pdf (10/6/2018).

» Secretaría de Servicios Públicos, CAF, Universidad Nacional de Cuyo (s/f). Plan Integral de Movilidad Sustentable Área Metropolitana del Gran Mendoza, 2030. Mendoza.

"Secretaría de Servicios Públicos, Gobierno de Mendoza (2018). Red a licitar. Mendoza: Mendoza Gobierno. Recuperado de http://www.prensa.mendoza. gov.ar/wp-content/uploads/sites/5/2018/01/Presentaci\%C3\%B3n-Propuestade-Red-a-licitar-2018-1.pdf (3/3/2019).

»Secretaría de Servicios Públicos, Gobierno de Mendoza (s/f). Mendoza: Mendotran. Recuperado de https://Mendotran.com.ar/ (1/3/2019).

\section{Julieta Dalla Torre / julietadallatorre@gmail.com}

Licenciada en Sociología (Universidad Nacional de Cuyo), Doctora en Ciencias Sociales (Facultad Latinoamericana de Ciencias Sociales, FLACSO, Argentina). Investigadora asistente de CONICET (IMESC-IDEHESI, Mendoza) y docente e investigadora de la Universidad Nacional de Cuyo (FCPyS). Su línea de investigación se inserta en los estudios urbanos con énfasis en procesos de segregación social, fragmentación espacial y fronterización, fundamentalmente ligados a situaciones de pobreza y exclusión. 